\title{
Axial Compression Behavior of Ferrocement Geopolymer HSC Columns
}

\author{
Taha Awadallah El-Sayed
}

Citation: El-Sayed, T.A. Axial

Compression Behavior of

Ferrocement Geopolymer HSC

Columns. Polymers 2021, 13, 3789

https://doi.org/10.3390/

polym13213789

Academic Editors: Andrzej Puszka and Beata Podkościelna

Received: 5 October 2021

Accepted: 28 October 2021

Published: 1 November 2021

Publisher's Note: MDPI stays neutral with regard to jurisdictional claims in published maps and institutional affiliations.

Copyright: (C) 2021 by the author. Licensee MDPI, Basel, Switzerland. This article is an open access article distributed under the terms and conditions of the Creative Commons Attribution (CC BY) license (https:/ / creativecommons.org/licenses/by/ $4.0 /)$.
Structural Engineering Department, Faculty of Engineering at Shoubra, Benha University, Cairo 11629, Egypt; taha.ibrahim@feng.bu.edu.eg

\begin{abstract}
Geopolymer concrete (GC) is a substantial sort that is created by utilizing metakaolin, ground granulated blast furnace slag (GGBS), silica fumes, fly ash, and other cementitious materials as binding ingredients. The current study concentrated on the structural behavior of the ferrocement geopolymer HSC-columns subjected to axial loading and produced using rice straw ash (RSA). The major goal of this research was to use the unique features of the ferrocement idea to manufacture members that function as columns bearing members. As they are more cost-effective and lower in weight, these designed elements can replace traditional RC members. The study also intended to reduce the cost of producing new parts by utilizing low-cost materials such as light weight expanded and welded wire meshes, polyethylene mesh (Tensar), and fiber glass mesh. For this purpose, an experimental plan was conducted and a finite element prototype with ANSYS2019-R1 was implemented. Nine geopolymer ferrocement columns of dimensions of $150 \mathrm{~mm} \times 150 \mathrm{~mm} \times 1600 \mathrm{~mm}$ with different volume-fraction and layers as well as a number of metallic and nonmetallic meshes were examined under axial compression loading until failure. The performance of the geopolymer columns was examined with consideration to the mid-span deflection, ultimate failure load, first crack load with various phases of loading, the cracking patterns, energy absorption and ductility index. Expanded or welded ferrocement geopolymer columns showed greater ultimate failure loads than the control column. Additionally, using expanded or welded columns had a considerable effect on ultimate failure loads, where the welded wire mesh exhibited almost $28.10 \%$ compared with the expanded wire mesh. Columns reinforced with one-layer of nonmetallic Tensar-mesh obtained a higher ultimate failure load than all tested columns without concrete cover spalling. The analytical and experimental results were in good agreement. The results displayed an accepted performance of the ferrocement geopolymer HSC-columns.
\end{abstract}

Keywords: axial behavior; geopolymer concrete (GC); ferrocement; finite element analysis (FEA)

\section{Introduction}

The utilization of industrial by-products in the construction area is an important means of reducing construction costs and the safe removal of manufacturing waste [1-5]. In this sense, the straight use of alkaline fly ash and GGBS is recycled to manufacture geopolymer-cement for special construction concrete manufacturing [6,7]. The energy employed in geopolymer-cement production is much less than that used in OPC, which is directly affected by greenhouse gases [7]. In some adverse environmental conditions where OPCs are not very resistant, new and alternative concretes such as geopolymer-concrete need to be developed.

Most constructions use concrete hoists where OPC is used as the main binder. As a civil engineer, a lot is known regarding the environmental issues in the cement industry. The amount of carbon dioxide produced inside the atmosphere is equal to the manufacture of cement and it is similarly known that the energy required to produce cement is high, which consumes more fossil fuels $[8,9]$. When the cement is partially replaced in the existence of polymers and water at room temperature, the fly ash interacts with calcium 
hydroxide through the hydration procedure to produce a (C-S-H) gel. The application and development of large quantities of fly-ash in concrete has made it possible to replace cement up to $60 \%$ with a concrete mass [8].

Over the course of several years, wide-ranging research has been conducted to confirm the possibility of using GC as a building material [6,7,10-14].

The use of GC is gradually rising, particularly for chemical resistant structures in industries, and research is ongoing to expand the variety of applications. In fact, significant experimental work has been performed in Australia, the United States, and Spain. Several investigators have offered suitable starting materials for the production, stiffness, mix design, mechanical properties, and durability of GC $[2,15,16]$. The bearing capacity and stiffness of geopolymer concrete columns are influenced by the compressive strength of the material. Larger compressive strength geopolymer concrete columns provide a higher bearing capacity, stiffness, and ductility.

Ordinary concrete columns have a lower bearing capacity and rigidity than geopolymer concrete columns. In engineering applications, geopolymer concrete columns can meet the design requirements for structural columns with sufficient load capacity, stiffness, and ductility.

Mansur and Paramasivan [17] carried out a test study on ferrocement columns under centric and eccentric compressive loads. Test findings indicated that a ferrocement column could be used as a structural column. Kaushik et al. [18] executed a study on ferrocement $\mathrm{RC}$ columns and realized that the ferrocement enhanced the strength and ductility of the columns for centric and eccentric compressive loads. Similarly, various studies have been undertaken on different ferrocement structural elements under centric and eccentric compressive loads [19-27].

The major goal of this research was to use the unique features of the ferrocement idea to manufacture members that function as column bearing members. As they are more costeffective and lower in weight, these designed elements can replace traditional RC members. The study also intended to reduce the cost of producing new parts by utilizing low-cost materials such as light weight expanded and welded wire meshes, polyethylene mesh (Tensar), and fiber glass mesh. Therefore, the main reason for this research was to examine the influence of the performance of RSA based geopolymer ferrocement HSC-columns under an axial compression load with various kinds and number of layers of metallic and nonmetallic meshes. For this purpose, an experimental plan was conducted and a finite element prototype with ANSYS2019-R1 was implemented. Nine geopolymer ferrocement columns with dimensions of $150 \mathrm{~mm} \times 150 \mathrm{~mm} \times 1600 \mathrm{~mm}$ were examined under axial compression loading until failure. The variables in this investigation were the mesh types and number of layers. The performance of the geopolymer columns was examined with consideration of the mid-span deflection, ultimate failure load, first crack load with various phases of loading, the cracking patterns, energy absorption, and ductility index.

\section{Experimental Study}

This experimental program was conducted in the Housing and Building National Research Center-Dokki-Egypt. A 5000-kN capacity test machine capable of testing columns up to $6 \mathrm{~m}$ in height was used to test the columns. The main aim was to find the ultimate deflection, ultimate load, and failure mode of the GC columns.

\subsection{Materials}

1. Fine aggregate: Sand with 2.55 specific gravity and bulk density $1780 \mathrm{~kg} / \mathrm{m}^{3}$. According to the Egypt Standard Specification (ESS) 203/2020 [28], a sieve analysis was performed. The results of the sieve analysis and the physical property test results are shown in Table 1 and Figure 1. 
Table 1. Physical properties of the sand.

\begin{tabular}{ccc}
\hline Property & Results & ESS Acceptance Limits \\
\hline Specific gravity $\left(\mathrm{kg} / \mathrm{m}^{3}\right)$ & 2.55 & - \\
\hline Bulk density $\left(\mathrm{kg} / \mathrm{m}^{3}\right)$ & 1780 & Less than $4 \%$ \\
\hline $\begin{array}{c}\text { Materials finer than no. 200, } \\
\text { sieve }(0.074 \mathrm{~mm}) \%\end{array}$ & 1.4 & \\
\hline
\end{tabular}

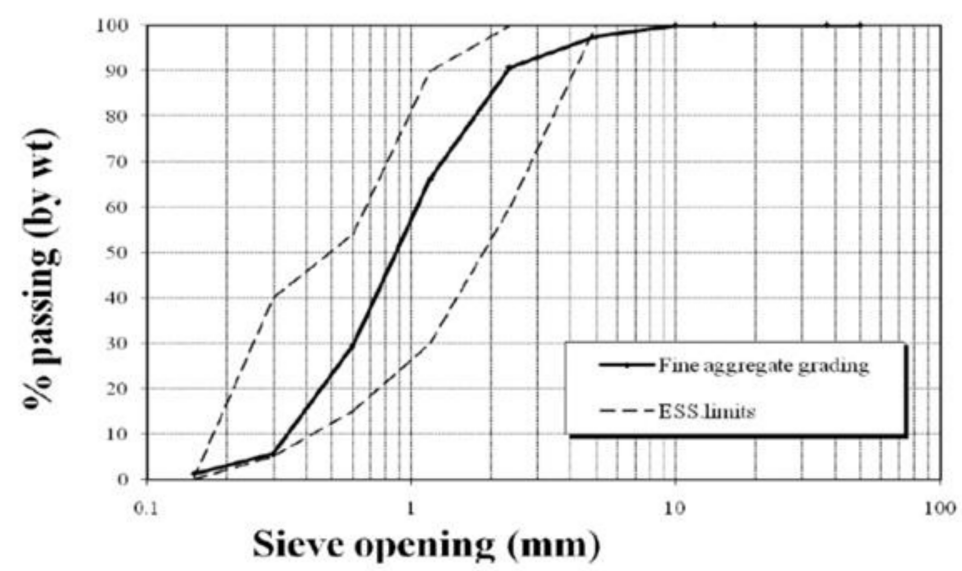

Figure 1. Fine aggregate grading curve.

2. Coarse aggregate: Crushed aggregate with size $10 \mathrm{~mm}, 2.60$ specific gravity and bulk density $1750 \mathrm{~kg} / \mathrm{m}^{3}$. According to the Egypt Standard Specification (ESS) 203/2020 [28], sieve analysis was performed. The aggregate mechanical and physical properties are shown in Table 2, and the grading is shown in Figure 2.

Table 2. The physical and mechanical properties of the coarse aggregate.

\begin{tabular}{ccc}
\hline Property & Results & ESS Acceptance Limits \\
\hline Specific gravity $\left(\mathrm{kg} / \mathrm{m}^{3}\right)$ & 2.2 .60 & - \\
\hline Unit weight $\left(\mathrm{kg} / \mathrm{m}^{3}\right)$ & 1750 & - \\
\hline Absorption Percentage & $1.46 \%$ & No more than $2.5 \%$ \\
\hline
\end{tabular}

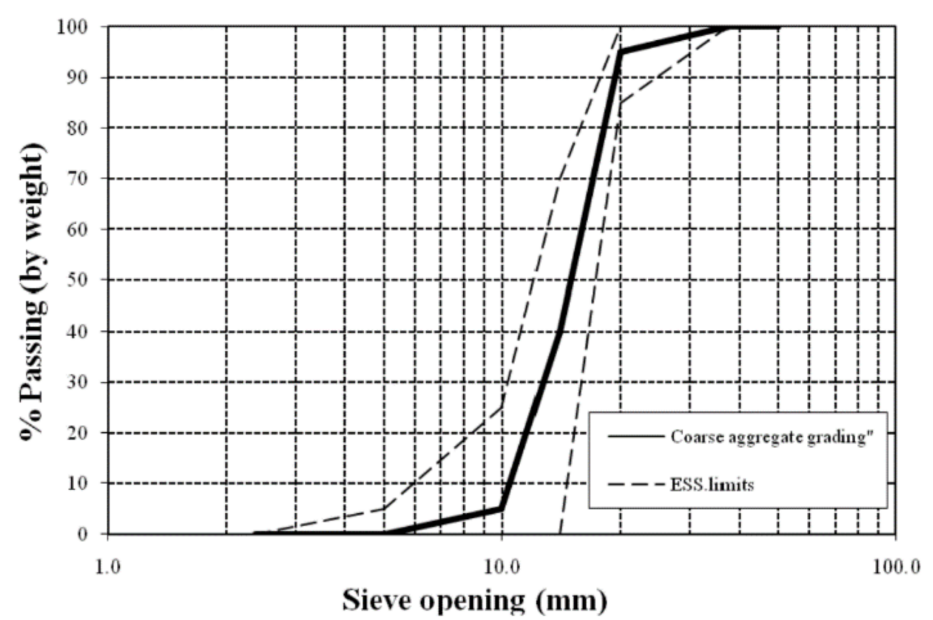

Figure 2. Coarse aggregate grading curve. 
3. Recycled Rice-Straw-Ash (RSA): RSA with a specific gravity $2.91 \mathrm{~g} / \mathrm{cm}^{2}$, and specific surface area of $5200 \mathrm{~cm}^{2} / \mathrm{g}$.

4. Water: used for mixing and curing.

5. Alkaline activator: sodium meta-silicate $\left(\mathrm{Na}_{2} \mathrm{SiO}_{3}\right)$ and sodium hydroxide $(\mathrm{NaOH})$.

6. Steel RFT: Two types of steel were used. Plain bars (24/35) with a $6 \mathrm{~mm}$ diameter, and deformed bars $(42 / 60)$ with a $12 \mathrm{~mm}$ diameter.

7. Steel wire-meshes:

(a) Welded and expanded wire-mesh: Figure 3 shows the types of ferrocement meshes used. Table 3 shows the mechanical properties of the welded and expanded steel wire-meshes.

(b) Polyethylene (Tensar)-mesh: This mesh is made from the high density polyethylene, "Geogrid CE 121", as shown in Figure 4, with an opening size of $6 \mathrm{~mm} \times 8 \mathrm{~mm}$, thickness of $3.3 \mathrm{~mm}$, volume fraction of $2.04 \%$, and weight of $725 \mathrm{gm} / \mathrm{m}^{2}$.

(c) Fiber glass mesh: Gavazzi "V3-133-A" was used with an opening dimension of $12.5 \mathrm{~mm} \times 11.5 \mathrm{~mm}$. The cross-section dimension $1.66 \mathrm{~mm} \times 0.66 \mathrm{~mm}$ (longitudinal direction) and $1.0 \mathrm{~mm} \times 0.5 \mathrm{~mm}$ (transverse direction) as shown in Figure 5. The mesh has a volume fraction of $0.535 \%$ and weight of $123 \mathrm{gm} / \mathrm{m}^{2}$.

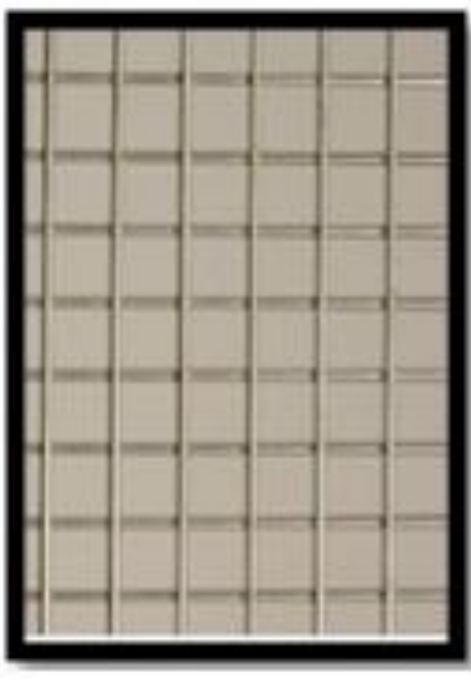

(a)

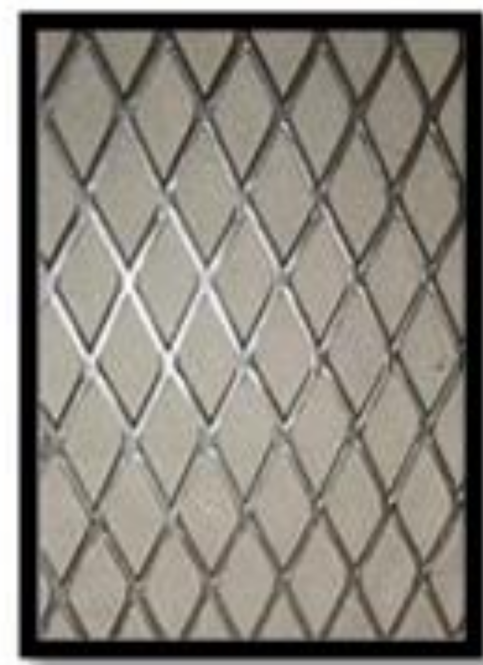

(b)

Figure 3. Types of meshes. (a) Welded wire-mesh, (b) Expanded wire-mesh [29].

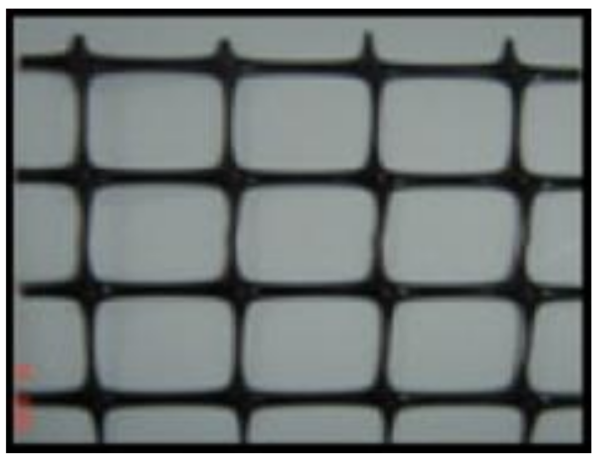

Figure 4. Polyethylene (Tensar) mesh. 


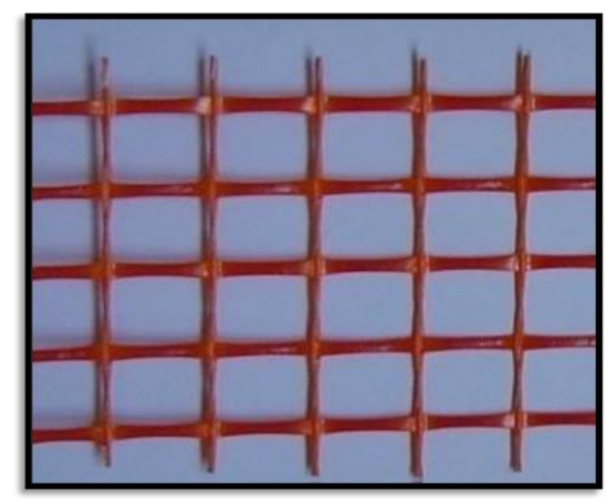

Figure 5. Fiber glass mesh.

Table 3. Mechanical properties of the welded and expanded wire-meshes [29].

\begin{tabular}{cccc}
\hline \multicolumn{2}{c}{ Welded Wire Mesh } & \multicolumn{2}{c}{ Expanded Wire Mesh } \\
\hline Dimensions size & $12.5 \times 12.5 \mathrm{~mm}$ & Dimensions size & $16.5 \times 31 \mathrm{~mm}$ \\
\hline Weight & $600 \mathrm{gm} / \mathrm{m}^{2}$ & Weight & $1660 \mathrm{gm} / \mathrm{m}^{2}$ \\
\hline Thickness & $0.7 \mathrm{~mm}$ & Wire Diameter & $1.25 \mathrm{~mm}$ \\
\hline Young's Modulus & $17000 \mathrm{~N} / \mathrm{mm}^{2}$ & Young's Modulus & $12000 \mathrm{~N} / \mathrm{mm}^{2}$ \\
\hline Yield Stress & $400 \mathrm{~N} / \mathrm{mm}^{2}$ & Yield Stress & $250 \mathrm{~N} / \mathrm{mm}^{2}$ \\
\hline Yield Strain & $1.17 \times 10^{-3}$ & Yield Strain & $9.7 \times 10^{-3}$ \\
\hline Ultimate Strength & $600 \mathrm{~N} / \mathrm{mm}^{2}$ & Ultimate Strength & $380 \mathrm{~N} / \mathrm{mm}^{2}$ \\
\hline Ultimate Strain & $58.5 \times 10^{-3}$ & Ultimate Strain & $59.2 \times 10^{-3}$
\end{tabular}

\subsection{Design of Mix}

Table 4 shows the mix design of the high strength concrete. The mix design was used to develop HSC at 28 days with a target strength of $60 \mathrm{MPa}$.

Table 4. Mix design of HSC.

\begin{tabular}{|c|c|c|c|c|c|c|}
\hline Item & $\begin{array}{c}\text { RSA } \\
\left(\mathrm{kg} / \mathrm{m}^{3}\right)\end{array}$ & $\begin{array}{c}\text { Coarse Aggregate } \\
\left(\mathrm{kg} / \mathrm{m}^{3}\right)\end{array}$ & $\begin{array}{c}\text { Fine Aggregate } \\
\left(\mathrm{kg} / \mathrm{m}^{3}\right)\end{array}$ & $\begin{array}{c}\mathrm{NaOH} \\
\left(\mathrm{kg} / \mathrm{m}^{3}\right)\end{array}$ & $\begin{array}{c}\mathrm{Na}_{2} \mathrm{SiO}_{3} \\
\left(\mathrm{~kg} / \mathrm{m}^{3}\right)\end{array}$ & $\begin{array}{c}\text { Water } \\
\left(\mathrm{kg} / \mathrm{m}^{3}\right)\end{array}$ \\
\hline Per $\mathrm{m}^{3}$ of concrete & 400 & 1150 & 650 & 50 & 150 & 47 \\
\hline
\end{tabular}

\subsection{Column Sample Description}

The experimental work was made to investigate the behavior, ultimate capacity, and crack-pattern of the geopolymer HSC columns. The experimental program consisted of (nine) geopolymer HSC columns with dimensions of $150 \mathrm{~mm} \times 150 \mathrm{~mm} \times 1600 \mathrm{~mm}$ reinforced with $(4 \varphi$ 12) steel bars. Columns were tested axially using a compression machine of capacity $5000 \mathrm{kN}$. The concrete dimensions of the columns and details of RFT are presented in Figure 6. All tested columns are presented in Table 5. Additionally, Table 6 shows the reinforcement configurations for all tested columns. 


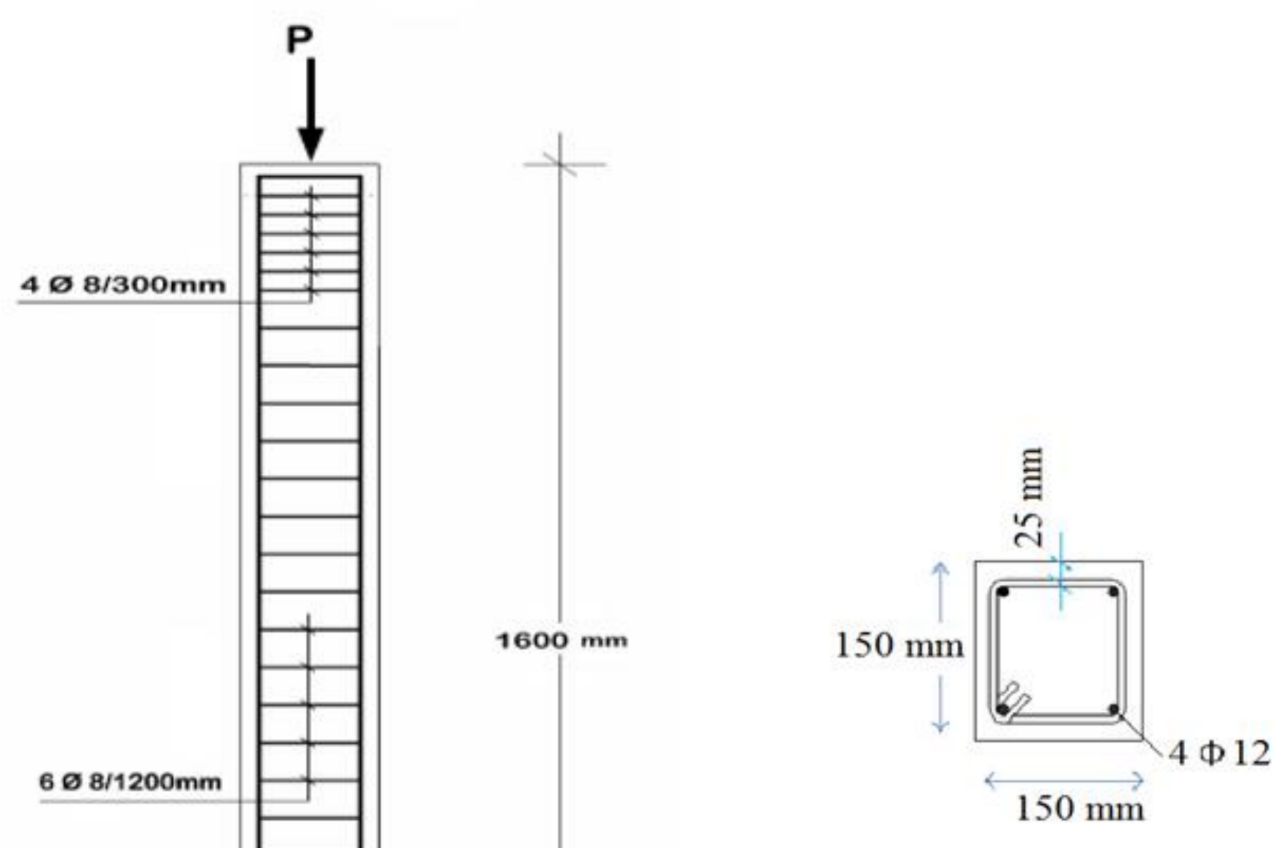

Table 5. Description of the studied columns.

\begin{tabular}{|c|c|c|c|c|c|}
\hline Series & $\begin{array}{c}\text { Sample } \\
\text { ID }\end{array}$ & Sample Description & Volume of Fraction & RFT. & Stirrups \\
\hline Control & $\mathrm{C} 1$ & Control & - & $4 \varphi 12$ & $6 \varphi 8 /{ }^{\prime}$ \\
\hline \multirow{3}{*}{ Group A: Welded wire-mesh } & C1-A & 1-layer welded & 0.00270 & $4 \varphi 12$ & $\longrightarrow$ \\
\hline & $\mathrm{C} 2-\mathrm{A}$ & 2-layers welded & 0.00540 & $4 \varphi 12$ & $\longrightarrow$ \\
\hline & C3-A & 3-layers welded & 0.00810 & $4 \varphi 12$ & - \\
\hline \multirow{2}{*}{ Group B: Expanded wire-mesh } & C4-B & 1-layer expanded & 0.00753 & $4 \varphi 12$ & - \\
\hline & C5-B & 2-layers expanded & 0.01510 & $4 \varphi 12$ & - \\
\hline Group C: Tensar-mesh & C6-C & 1-layer Tensar & 0.02040 & $4 \varphi 12$ & $\longrightarrow$ \\
\hline \multirow{2}{*}{ Group D: Fiber glass-mesh } & C7-D & 1-layer fiber glass & 0.00535 & $4 \varphi 12$ & - \\
\hline & C8-D & 2-layers fiber glass & 0.01070 & $4 \varphi 12$ & - \\
\hline
\end{tabular}


Table 6. Reinforcement configurations of the tested columns.

$\begin{array}{ccc}\begin{array}{c}\text { Sample } \\ \text { ID }\end{array} & \text { Tested Columns Reinforcement Configurations } \\ \mathrm{C} 1 & \end{array}$
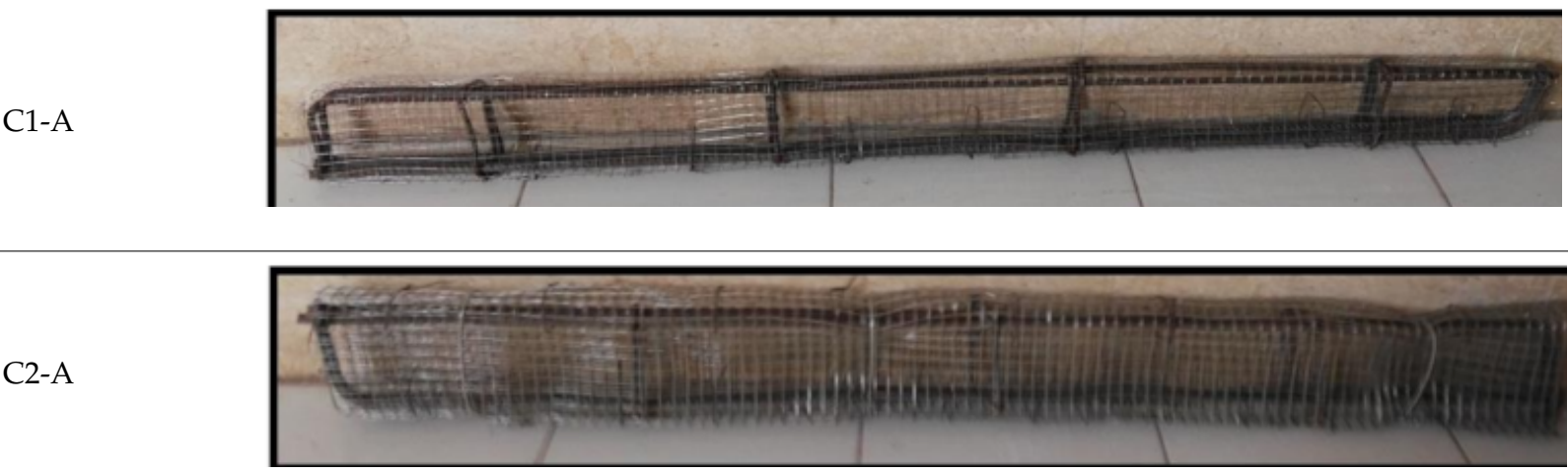

C3-A

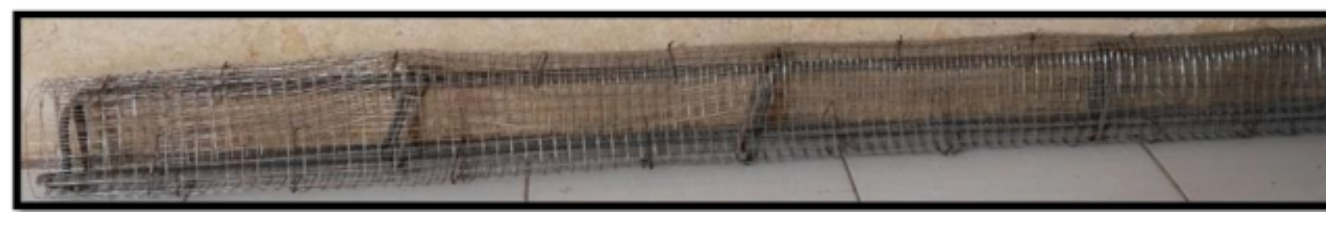

C4-B

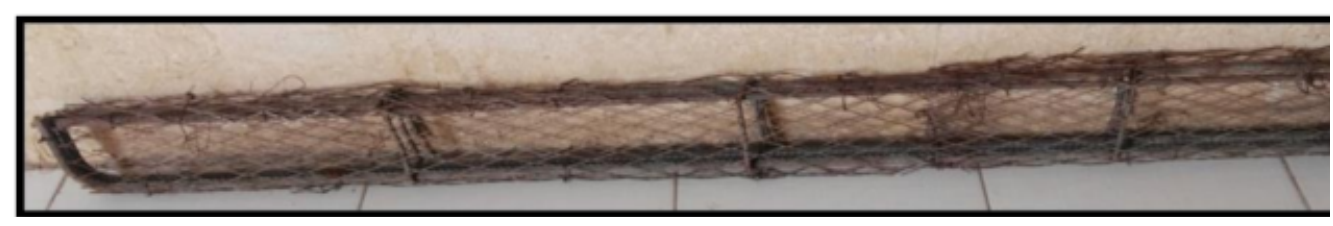

C5-B

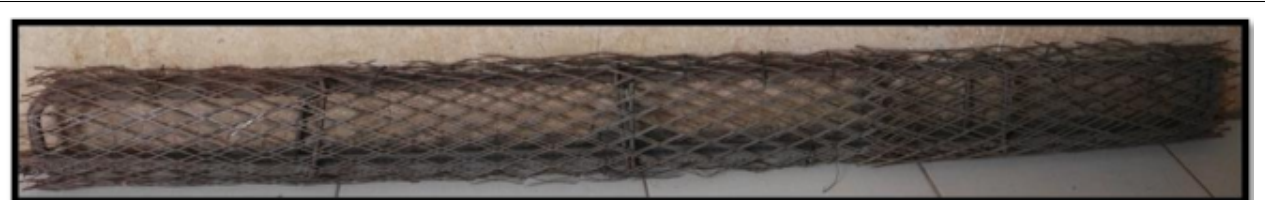

C6-C

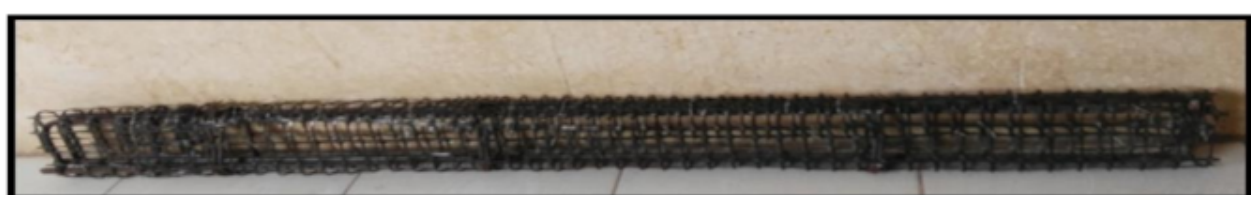

C7-D

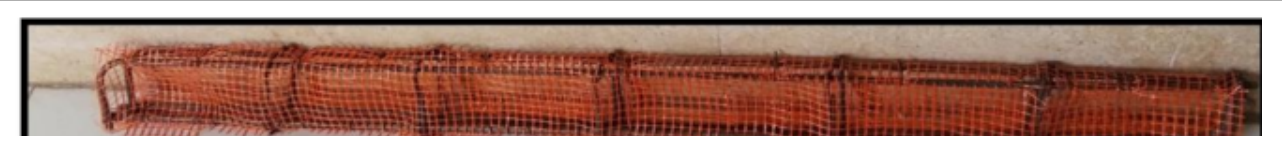

C8-D

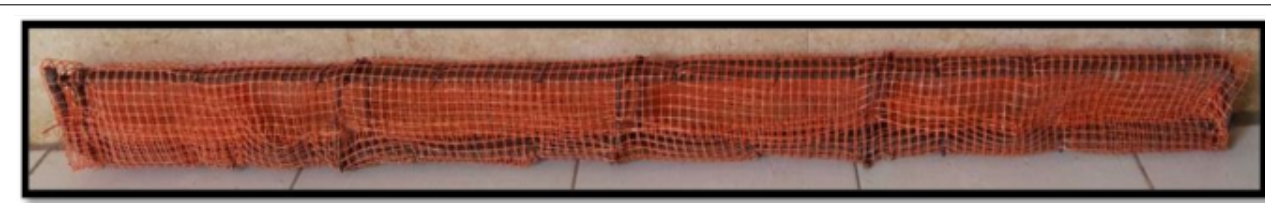




\subsection{Test Setup}

A compression test machine with a capacity of $5000 \mathrm{kN}$ was utilized to test all column samples. Figure 7 shows a typical test setup for the columns. The deflection was measured using LVDT and all were tested until failure.

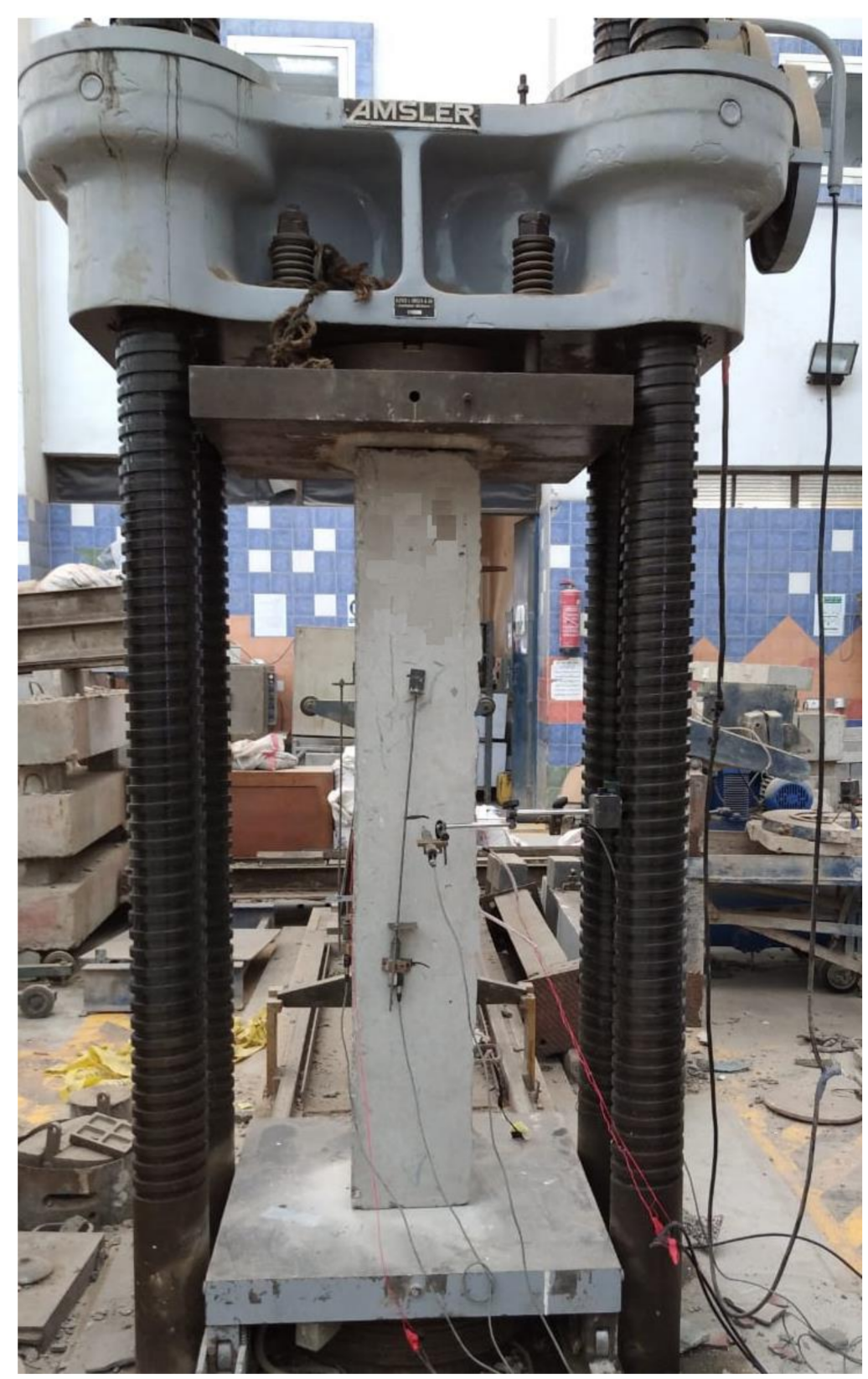

Figure 7. Test setup.

\section{Discussion of Results}

The behavior of the tested geopolymer HSC columns in terms of ultimate deflection, ultimate load, load-deflection relationship and failure mode, and cracking behavior are discussed as follows.

\subsection{Ultimate Load}

The ultimate loads for the tested columns are shown in Figure 11 and Table 7. The ultimate load of the control C1 was $738.70 \mathrm{kN}$. For group A, columns C1-A to C3-A, the ultimate loads extended between $771.80 \mathrm{kN}$ and $955.60 \mathrm{kN}$. The improvement in the 
ultimate capacity was $4.30 \%$ to $22.70 \%$. For group B, columns C4-B and C5-B, the ultimate loads extended between $813.70 \mathrm{kN}$ and $821.70 \mathrm{kN}$. The improvement in the ultimate capacity was $9.20 \%$ and $19.90 \%$. For group C, column C6-C, with an ultimate load of $1027.20 \mathrm{kN}$, there was a large considerable improvement of $28.10 \%$. For group D, columns C7-D and C8-D, the ultimate loads were $793.40 \mathrm{kN}$ and $841.30 \mathrm{kN}$, with an improvement of $7.20 \%$ and $12.20 \%$, respectively.

Table 7. Experimental test results.

\begin{tabular}{|c|c|c|c|c|c|c|c|}
\hline $\begin{array}{l}\text { Column } \\
\text { ID }\end{array}$ & $\begin{array}{c}\text { First Crack } \\
\text { Load } \\
(\mathbf{k N})\end{array}$ & $\begin{array}{c}\text { Serviceability } \\
\text { Load } \\
(\mathbf{k N})\end{array}$ & $\begin{array}{c}\text { Ultimate } \\
\text { Load } \\
(\mathbf{k N})\end{array}$ & $\begin{array}{l}\text { Def. at First } \\
\text { Crack Load } \\
(\mathrm{mm})\end{array}$ & $\begin{array}{c}\text { Def. at Ult. } \\
\text { load } \\
(\mathrm{mm})\end{array}$ & $\begin{array}{c}\text { Ductility } \\
\text { Ratio } \\
-\end{array}$ & $\begin{array}{l}\text { Energy Absorption } \\
(\mathrm{kN} \cdot \mathrm{mm})\end{array}$ \\
\hline $\mathrm{C} 1$ & 296.00 & 460.59 & 738.70 & 3.80 & 12.02 & 3.16 & 6320.08 \\
\hline C1-A & 325.00 & 481.27 & 771.80 & 4.30 & 12.72 & 2.96 & 9201.48 \\
\hline C2-A & 380.00 & 525.46 & 842.50 & 4.70 & 14.36 & 3.06 & 9353.37 \\
\hline C3-A & 455.00 & 596.15 & 955.60 & 5.20 & 14.50 & 2.79 & $10,380.91$ \\
\hline C4-B & 443.00 & 507.46 & 813.70 & 5.90 & 15.45 & 2.62 & $10,122.72$ \\
\hline C5-B & 449.00 & 574.96 & 921.70 & 6.30 & 16.96 & 2.69 & $12,008.52$ \\
\hline C6-C & 515.00 & 640.90 & 1027.20 & 4.40 & 13.55 & 3.08 & $10,414.93$ \\
\hline C7-D & 391.00 & 496.65 & 796.40 & 3.90 & 12.08 & 3.10 & 6983.16 \\
\hline C8-D & 378.00 & 524.71 & 841.30 & 4.50 & 14.07 & 3.13 & 9179.36 \\
\hline
\end{tabular}

According to the findings in Table 7, the use of fiber glass mesh is more efficient than other types of metallic and nonmetallic mesh reinforcements in increasing the ultimate capacity.

\subsection{Ultimate Deflection}

Figure 12 and Table 7 show the ultimate deflection for all tested columns. The deflection for the control $\mathrm{C} 1$ was $12.02 \mathrm{~mm}$. For group $\mathrm{A}$, the maximum deflection ranged from $12.72 \mathrm{~mm}$ to $14.50 \mathrm{~mm}$ for columns C1-A to C3-A, which were higher than that of the control C1. For group B, the maximum deflection at ultimate load was $15.45 \mathrm{~mm}$ and $16.96 \mathrm{~mm}$ for columns $\mathrm{C} 4-\mathrm{B}$ and $\mathrm{C} 5-\mathrm{B}$ respectively, which was also higher than that of the control $\mathrm{C} 1$. For group C, column C6-C, had an ultimate deflection of $13.55 \mathrm{~mm}$. For group D, columns C7-D and C8-D, the ultimate deflections were 12.08 and $14.07 \mathrm{~mm}$, respectively.

\subsection{Load-Deflection Relationship}

The relationship between the load and the deflection for the tested columns is presented in Figure 8. From this figure, it can clearly be seen that for all columns, the relationship between the load and deflection can be divided into three stages as follows:

1. Elastic behavior until the first cracking. The load-deflection relationship in this stage is linear. The slope of the load deflection curve in this stage varies with different types of test specimens. The end of this stage is marked by the deviation from linearity.

2. In the second stage, the load-deflection curve slope changed slowly as a result of the samples' stiffness reduction due to the multiple cracking.

3. In the third stage, large plastic deformation occurred as the result of the yielding of the reinforcing bars and the large extension in the reinforcing mesh of the ferrocement columns. This stage is terminated by failure of the test columns. 


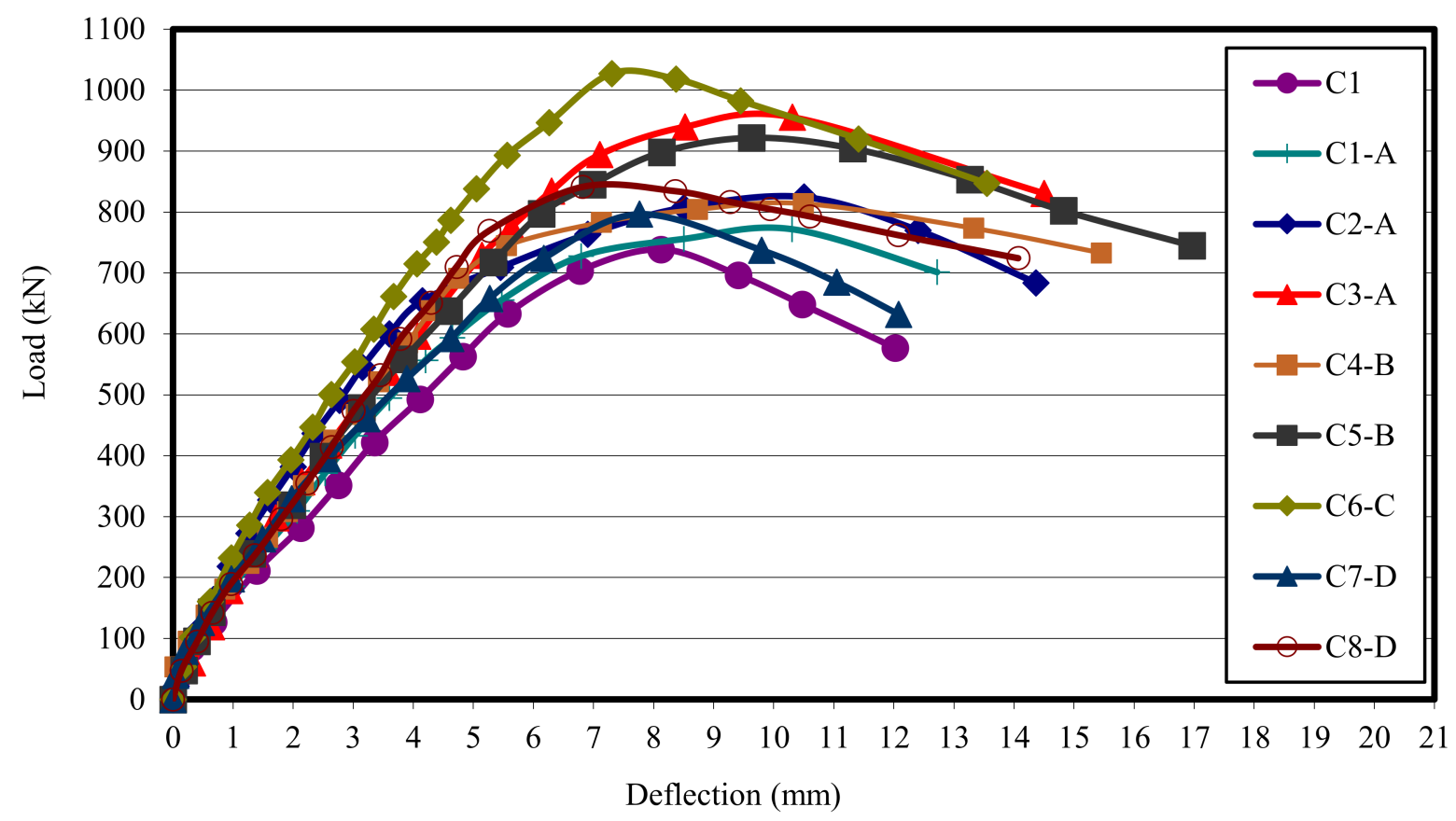

Figure 8. Comparison between the load deflection of all columns.

From Figure 9, it can be concluded that column C6-C, which was reinforced with one-layer of Tensar-mesh, had the highest first crack load and ultimate load, while the control column $\mathrm{C} 1$ had the lowest ultimate load carrying capacity.

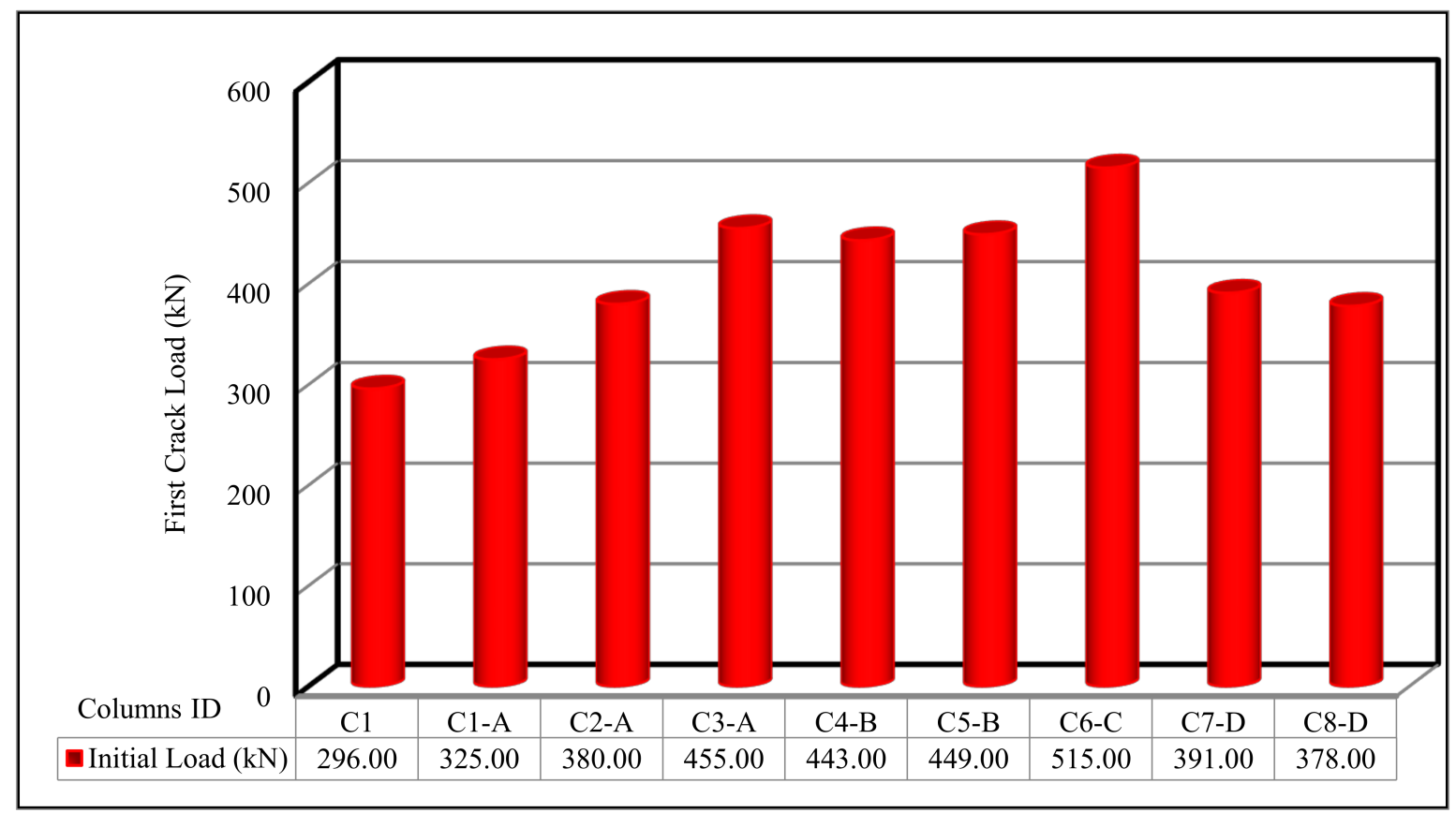

Figure 9. First crack load for the tested columns.

The results of all test specimens are listed in Table 7. This table shows the obtained results for the first crack load, service load, deflection at ultimate load, ductility ratio, and energy absorption. First crack load, ultimate load, and first crack and ultimate load deflection were gained throughout testing, but the ductility ratio, service load, and energy absorption were calculated from the load-deflection curve for each column sample. The first crack-load was obtained at the point at which the curve of load deflection began to 
deviate from the linear relationship. Furthermore, service load can be computed from Equation (1).

$$
P_{\text {ser }}=\frac{\left(P_{u l t}-1.4 \times \text { D.L. }\right)}{1.6}, \text { D.L. }=\text { own weight of column. }
$$

In the current section, the comparison between the behavior up to failure of the tested column as obtained from the experimental results is illustrated. The comparisons between all tested columns are shown in Figures 9-14, which show the first crack load, serviceability load, ultimate load, deflection at ultimate load, ductility ratio, and energy absorption for all tested columns, respectively.

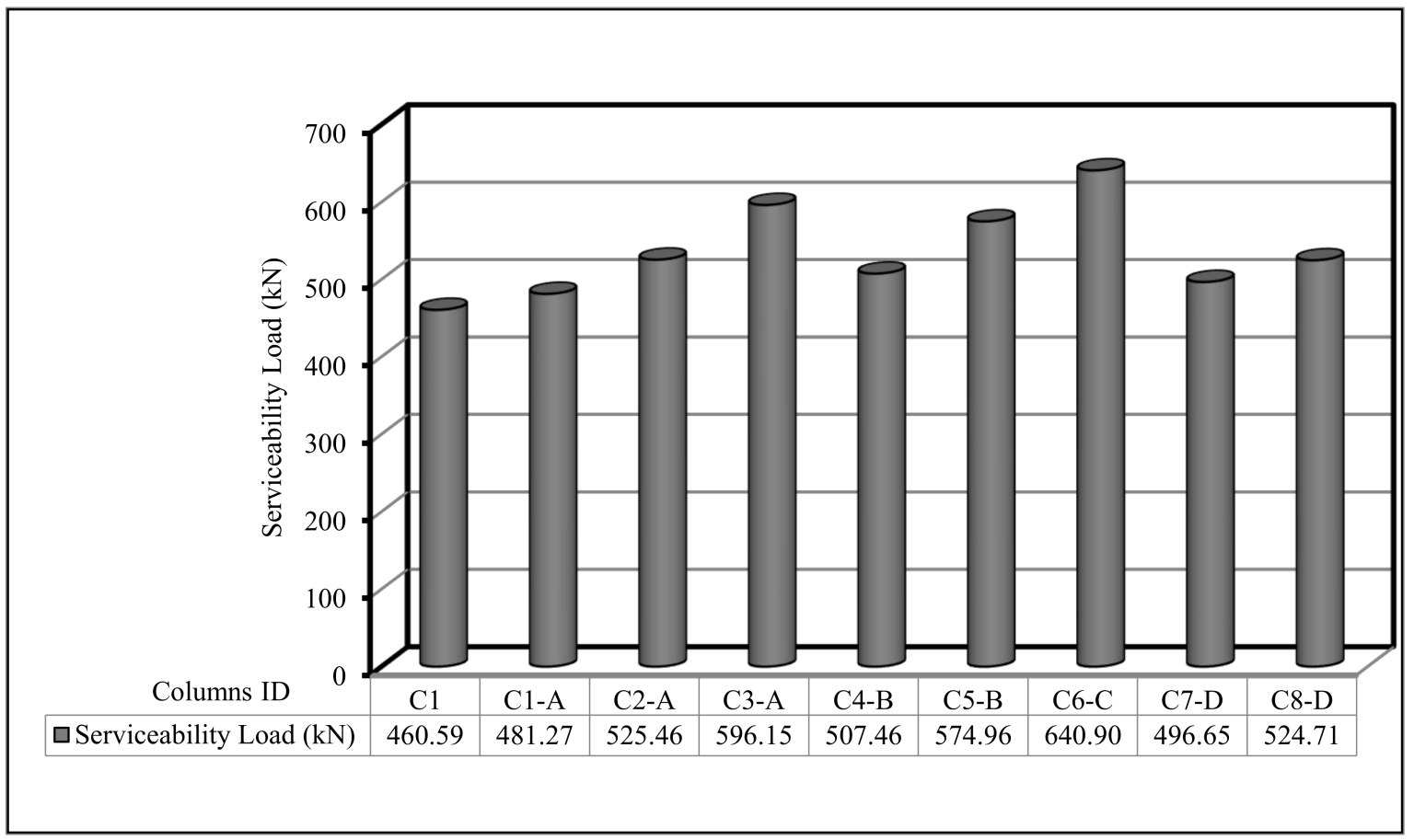

Figure 10. Serviceability load for the tested columns.

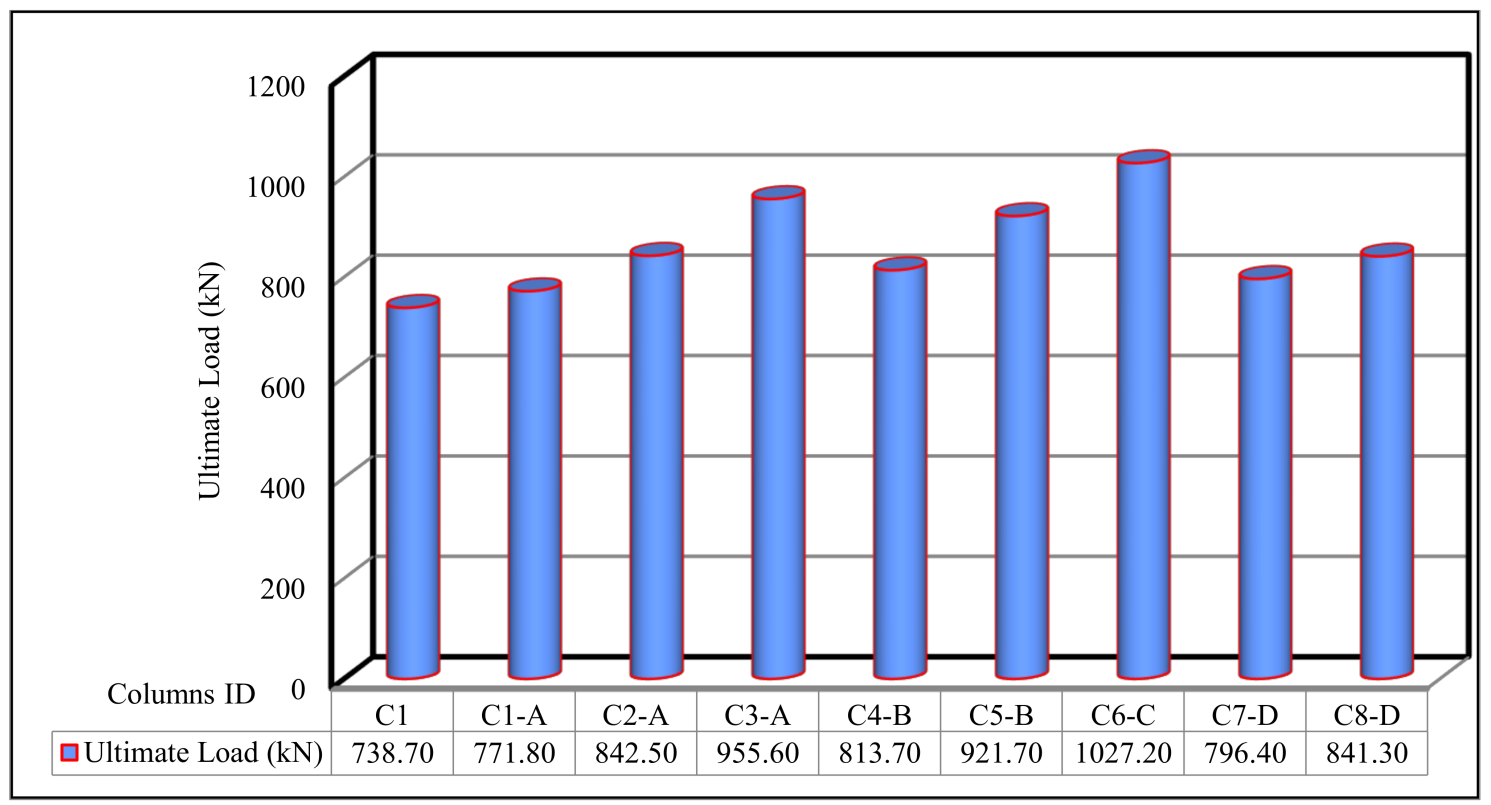

Figure 11. Ultimate load for the tested columns. 


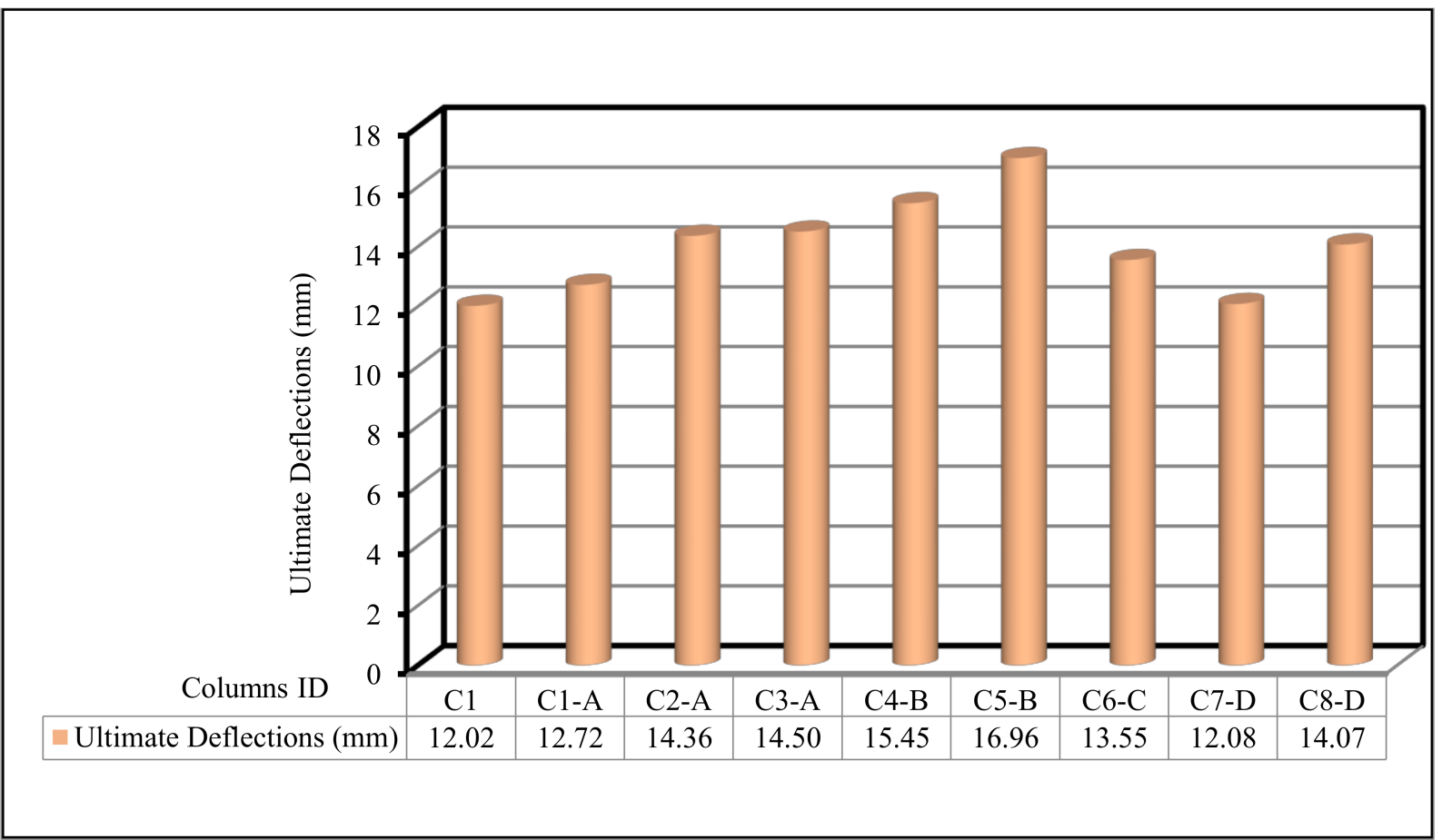

Figure 12. Ultimate deflection for the tested columns.

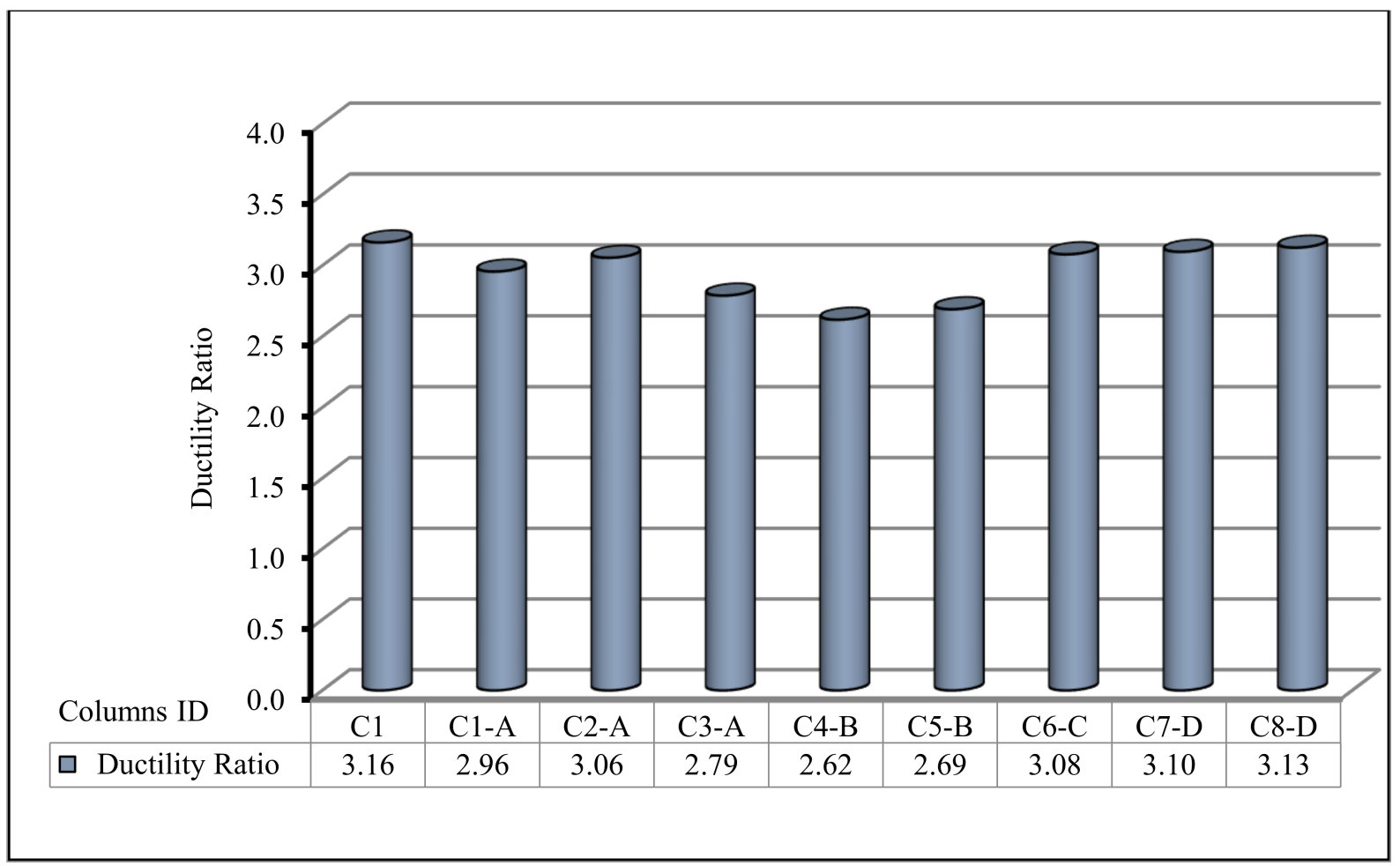

Figure 13. Ductility ratio for the tested columns. 


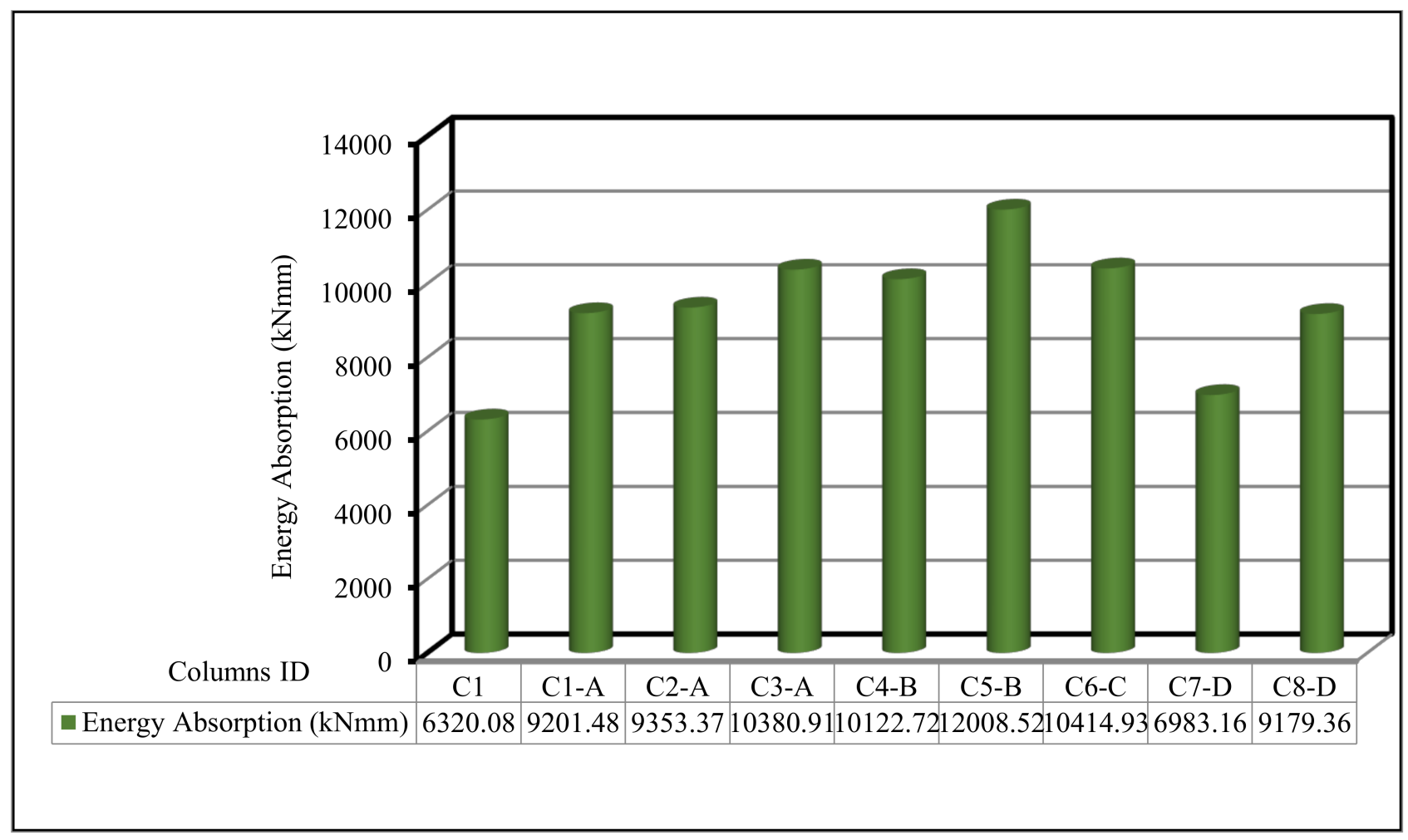

Figure 14. Energy absorption for the tested columns.

\subsection{Energy Absorption}

The ductility ratio was well-defined, similar to the proportion of the ultimate load deformation to the first crack load deformation, whereas the energy absorption was known as the area under the load deflection curve until collapse. Table 7 shows the ductility ratios and energy absorption values for all columns. Ongoing increase in the energy absorption as the volume fraction percentage increased, was noted. Column C8-D, with one layer of fiber glass mesh, had the highest ductility ratio when compared with the other types of meshes. Figure 14 shows the energy absorption comparison for all columns. The energy absorption for the control column $\mathrm{C} 1$ was $6320.08 \mathrm{kN} \cdot \mathrm{mm}$. For all other columns, the energy absorption was greater than the control $\mathrm{C} 1$. That is, it showed good enhancement with an enhancement percentage of $10 \%$ to $190 \%$. Group D with the fiber glass mesh exhibited the smallest enhancement whereas Group $C$ with the Tensar-mesh exhibited the highest enhancement. Column C5-B, which uses two layers of expanded wire mesh, had the highest energy absorption. It may be concluded that by improving the ductility ratio, these new composite materials improved the failure behavior.

Finally, the performance of columns was improved by employing these advanced composite materials. It may be said that it slowed the beginning of the first cracks, while also increasing the capacity of the service load. It also has high ultimate-loads, high durability, improved deformation, and improved energy absorption, all of which are advantageous in dynamic purposes.

\subsection{Crack Pattern}

Near collapse, the control column $\mathrm{C} 1$ showed a compression mode of failure with a concrete cover of local crushing and spalling. For all other tested columns, near collapse after the ultimate load value decreased up to $60 \%$ to $40 \%$ of the ultimate load. All crack patterns of the tested columns are shown in Figure 15. 

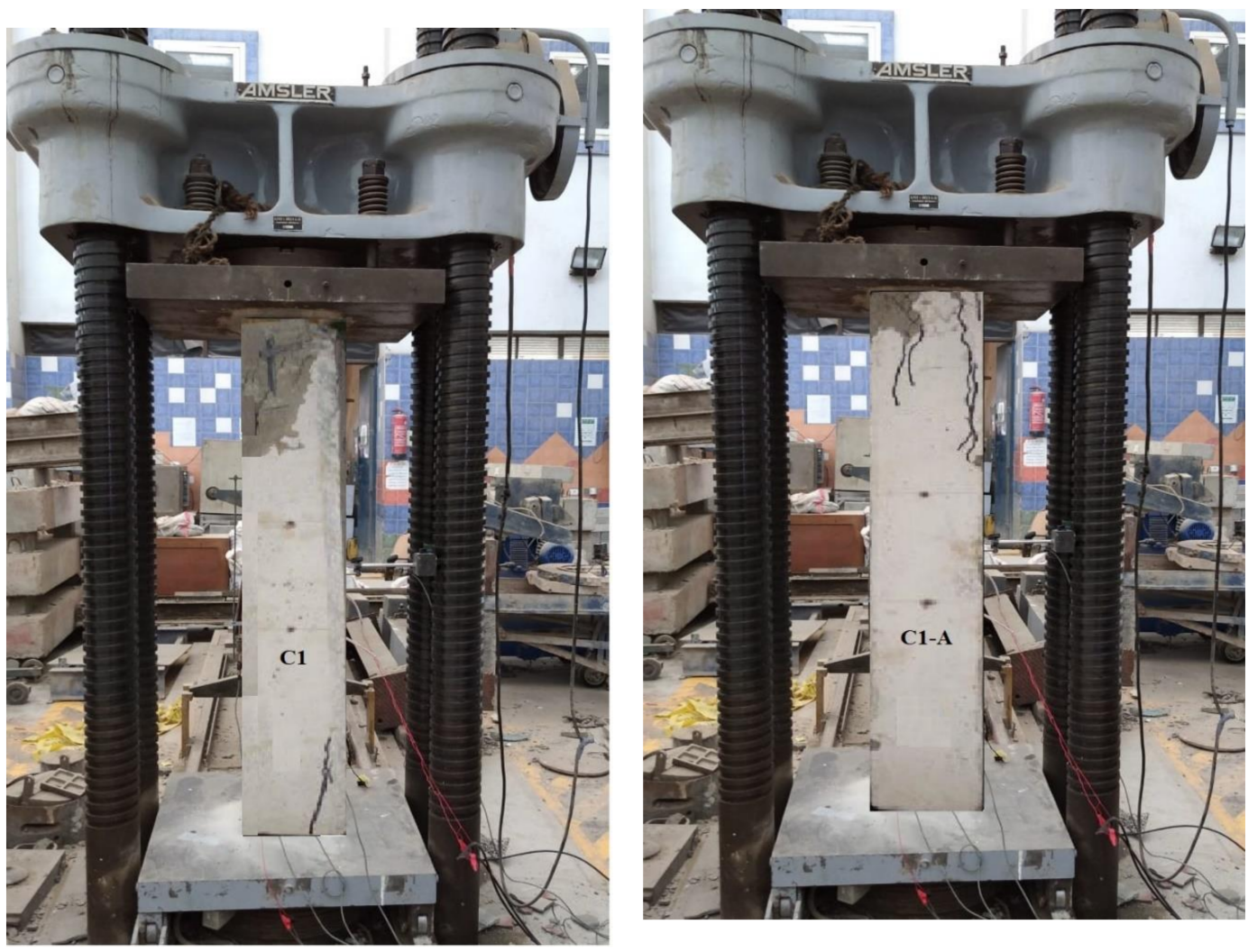

C1

C1-A

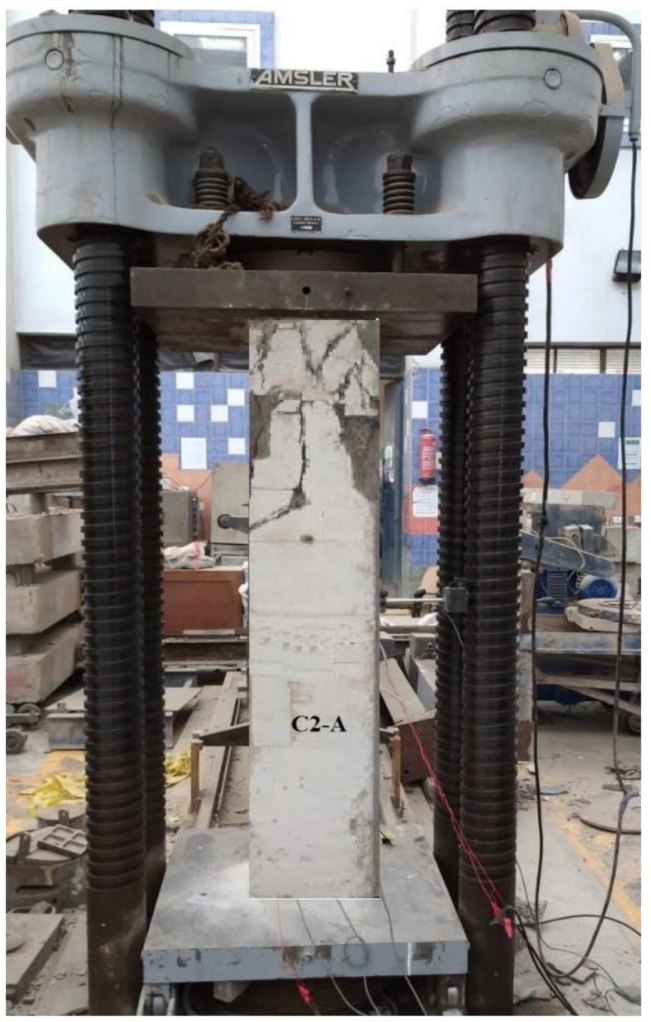

C2-A

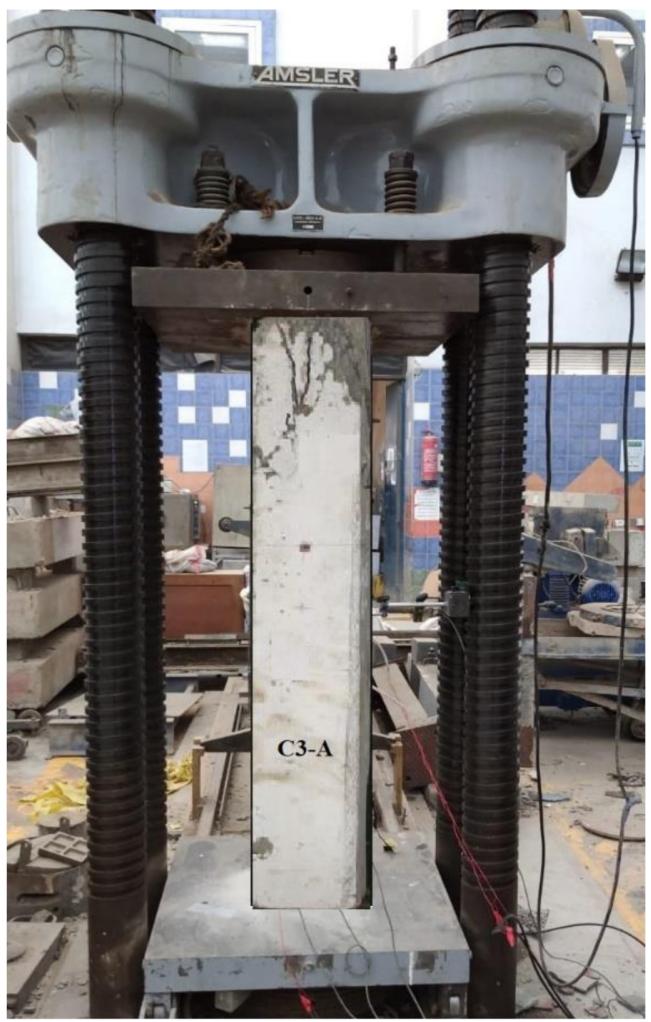

C3-A

Figure 15. Cont. 


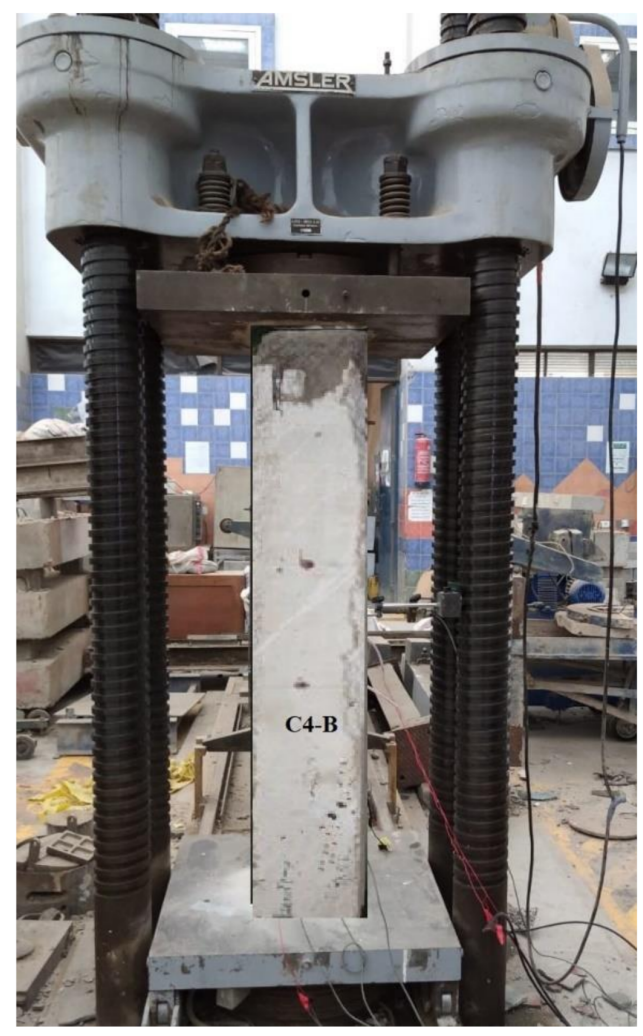

C4-B

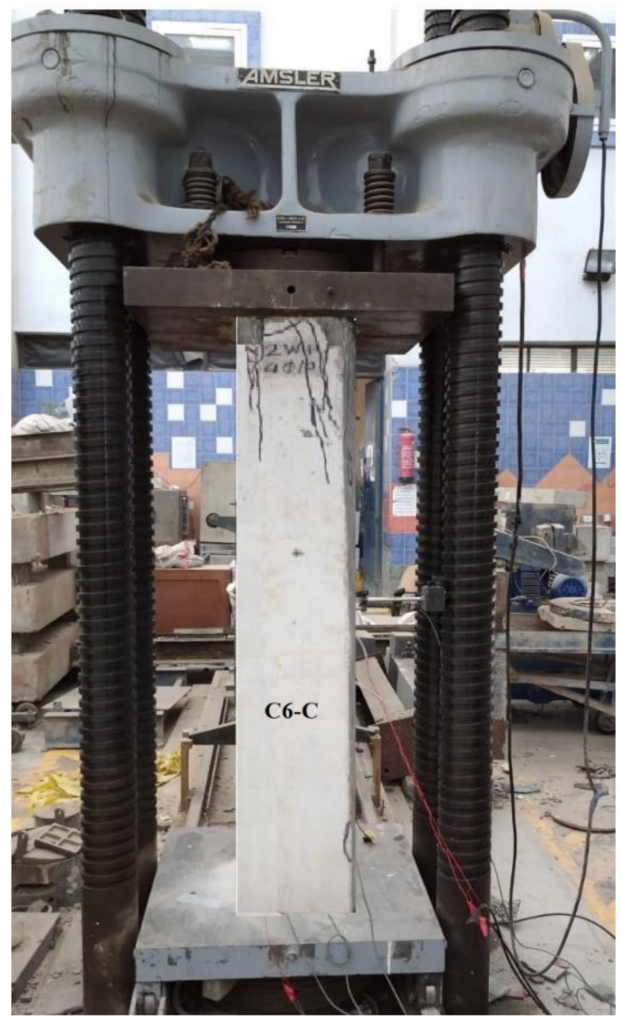

C6-C

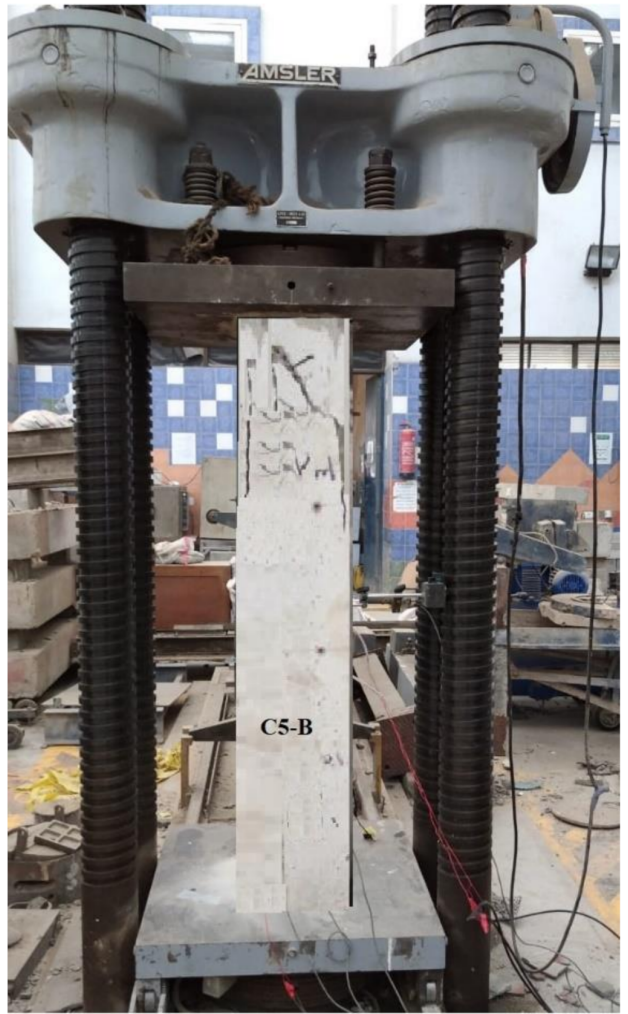

C5-B

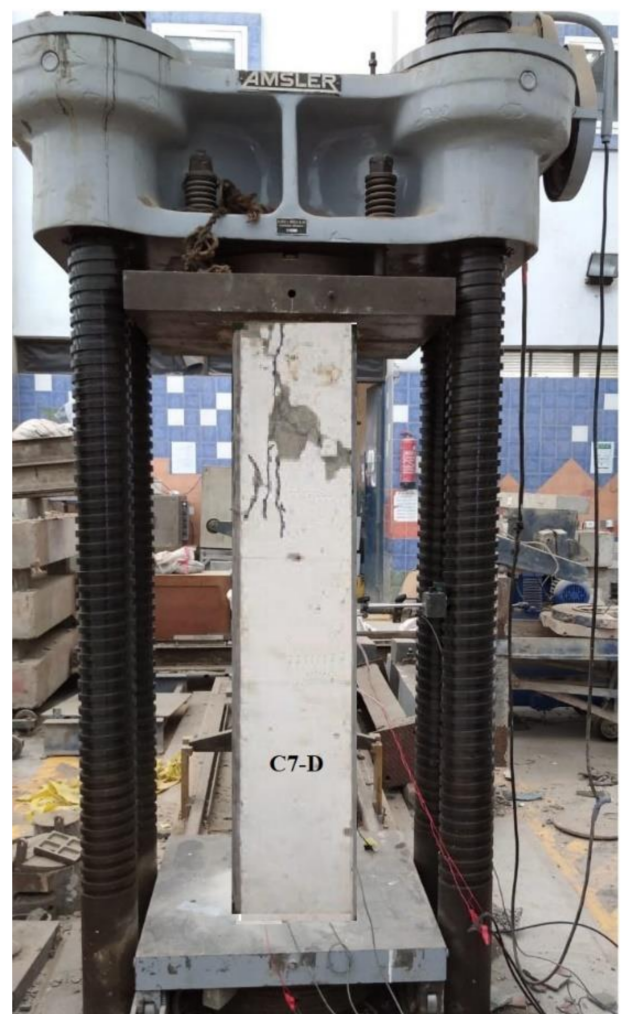

C7-D

Figure 15. Cont. 


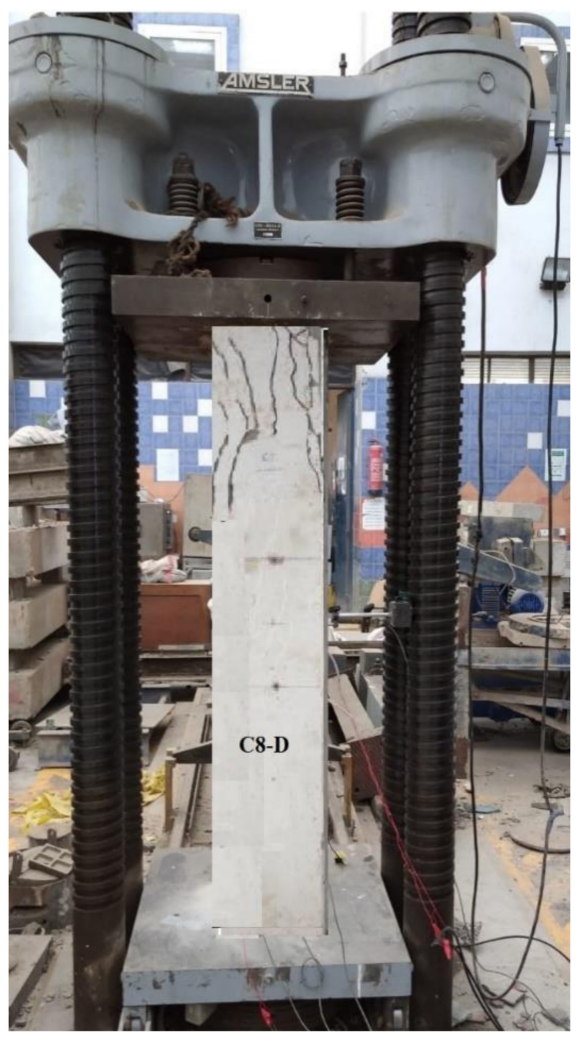

C8-D

Figure 15. Crack patterns.

\section{Analytical Analysis}

Analytical analysis was conducted to validate the results of the experimental program. Table 8 showed the analytical results were obtained from the NLFEA software ANSYS2019-R1 [30] program.

Table 8. Analytical results.

\begin{tabular}{ccccccc}
\hline $\begin{array}{c}\text { Column } \\
\text { ID }\end{array}$ & $\begin{array}{c}\text { First Crack Load } \\
\mathbf{( k N )}\end{array}$ & $\begin{array}{c}\text { Ultimate Load } \\
\mathbf{( k N )}\end{array}$ & $\begin{array}{c}\text { Def. at First } \\
\text { Crack Load } \\
\mathbf{( m m})\end{array}$ & $\begin{array}{c}\text { Def. at Ult. Load } \\
(\mathbf{m m})\end{array}$ & $\begin{array}{c}\text { Ductility Ratio } \\
-\end{array}$ & $\begin{array}{c}\text { Energy Absorption } \\
\mathbf{( k N} \cdot \mathbf{m m})\end{array}$ \\
\hline C1 & 260.30 & 812.57 & 2.85 & 8.12 & 2.85 & 4104.8310 \\
\hline C1-A & 260.30 & 848.98 & 3.23 & 10.30 & 3.19 & 6200.2411 \\
\hline C2-A & 260.30 & 906.95 & 3.53 & 10.50 & 2.98 & 7055.3147 \\
\hline C3-A & 260.30 & 1051.16 & 3.90 & 10.31 & 2.64 & 7303.0707 \\
\hline C4-B & 260.30 & 995.07 & 4.43 & 10.49 & 2.37 & 6899.9601 \\
\hline C5-B & 260.30 & 1013.87 & 4.73 & 9.63 & 2.04 & 6396.8092 \\
\hline C6-C & 260.30 & 1129.90 & 3.30 & 7.30 & 2.21 & 4933.7318 \\
\hline C7-D & 260.30 & 876.04 & 2.93 & 7.76 & 2.65 & 4237.6949 \\
\hline C8-D & 260.30 & 925.43 & 3.38 & 6.82 & 2.02 & 3782.9131 \\
\hline
\end{tabular}

\subsection{Types of Elements}

For concrete, element Solid 65 (Figure 16a) was used to represent the concrete stressstrain curve, while element Link 180 3-D (Figure 16b) was used to represent the reinforcing bars and reinforcing stirrups. All ferrocement reinforcement was modeled by computing 
the volumetric ratio (reinforcing steel ratio to concrete) in the concrete element Solid 65. As ANSYS allows the user to enter three rebar materials in the concrete, each material corresponds to $x, y$, and $z$. The orientation angles denoted the reinforcement orientation in the smeared model. Therefore, ferrocement reinforcements were modeled as smeared layers with the volumetric ratio as indicated in Section 4.2.

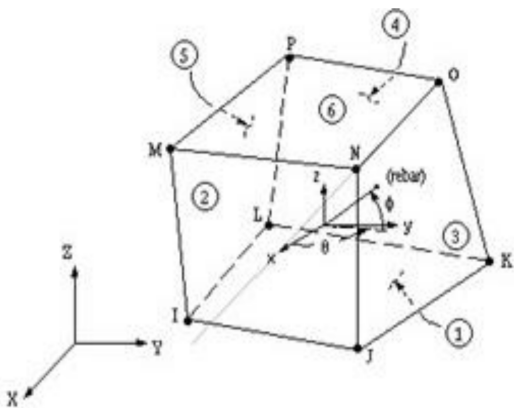

(a) Solid65

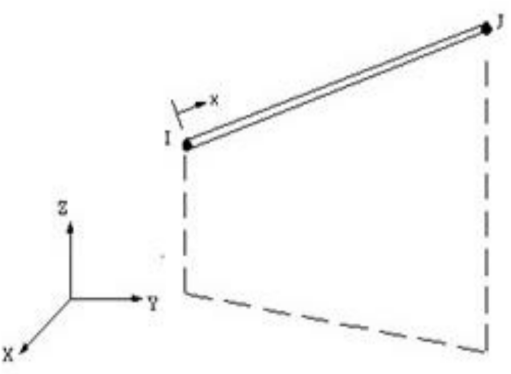

(b) Link180

Figure 16. Geometry of element types.

\subsection{Properties of Modeled Materials}

This section shows the material properties for concrete, reinforcing steel bars, and ferrocement wire meshes:

- The material properties for concrete:

1. Elastic modulus of elasticity $\left(\mathrm{Ec}=4400 \sqrt{ } \mathrm{fcu}=24,100 \mathrm{~N} / \mathrm{mm}^{2}\right)[28]$.

2. Poisson's ratio $(v=0.3)[28]$.

- The material properties for reinforcing steel bars:

1. Elastic modulus of elasticity $\left(E_{s}=200 \mathrm{kN} / \mathrm{mm}^{2}\right)$ [28].

2. Yield stress $\left(f_{y}=400 \mathrm{~N} / \mathrm{mm}^{2} \& f_{y s t}=240 \mathrm{~N} / \mathrm{mm}^{2}\right)$ [28].

3. Poisson's ratio $(v=0.2)[28]$.

4. Area of steel of $\varphi 12\left(\mathrm{As}=112 \mathrm{~mm}^{2}\right)$

5. Area of steel of $\varphi 8\left(\right.$ As $\left.=50.3 \mathrm{~mm}^{2}\right)$

- The properties for welded mire mesh:

1. Volumetric ratio of one layer $=0.0027$

2. Volumetric ratio of two layers $=0.0054$

3. Volumetric ratio of three layers $=0.0081$

- The material properties for Expanded wire mesh:

1. Volumetric ratio of one layer $=0.00753$

2. Volumetric ratio of two layers $=0.01510$

- The material properties for Tensar mesh:

1. Volumetric ratio of one layer $=0.02040$

- The material properties for glass fiber mesh:

1. Volumetric ratio of one layer $=0.00535$

2. Volumetric ratio of two layers $=0.01070$

\subsection{Specimens Modeling}

A finite nonlinear analysis was conducted to evaluate the behavior of geopolymer ferrocement HSC columns, as shown in Figure 17. 


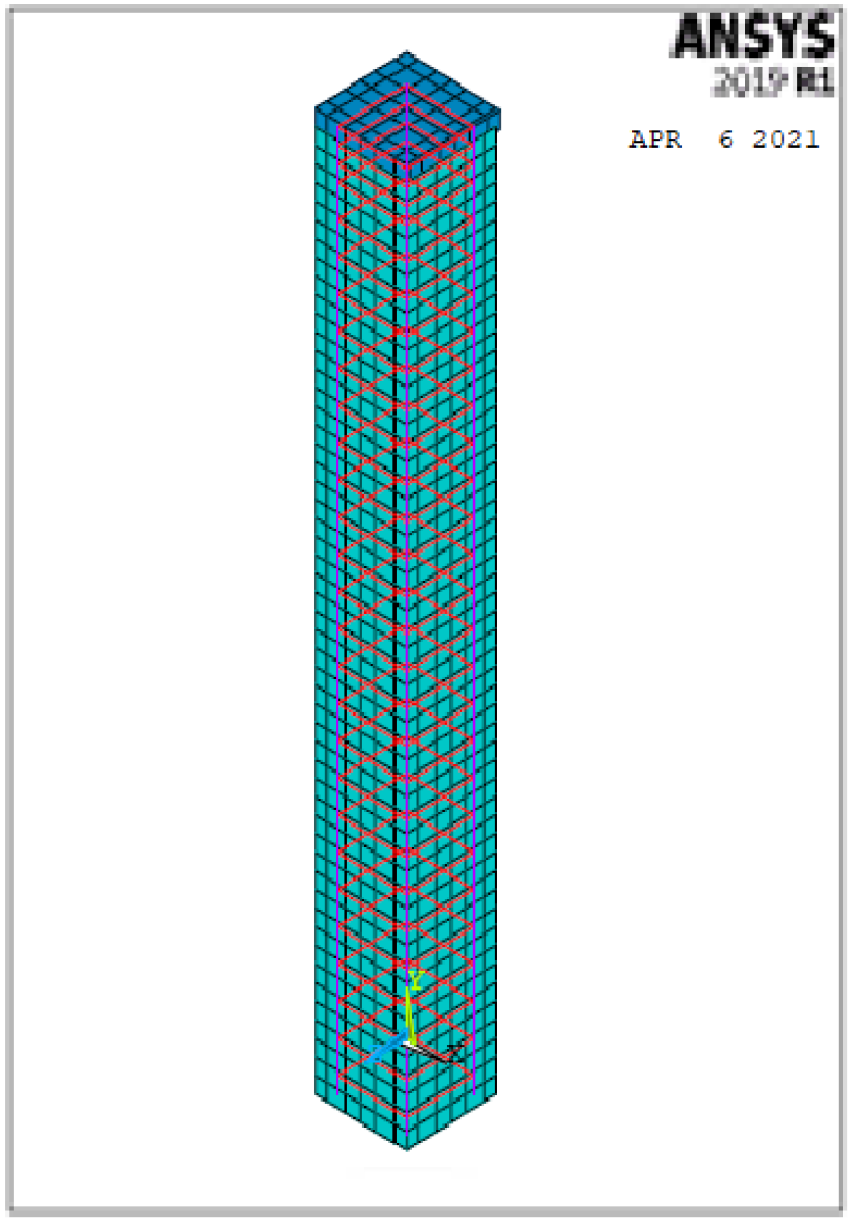

Figure 17. 3D-modeling of the columns.

\subsection{Analytical Results and Discussion}

Table 8 shows the analytical results such as the first crack load, ultimate load, the deflection at first crack and ultimate load, ductility ratio, and energy absorption for the modeled columns.

\subsubsection{Ultimate Load}

The ultimate loads for the modeled columns are shown in Table 8. The ultimate load of control C1 was $812.57 \mathrm{kN}$. For group A, columns C1-A to C3-A, the ultimate loads extended between $848.98 \mathrm{kN}$ and $1051.16 \mathrm{kN}$. The improvement in the ultimate capacity was $4.40 \%$ to $22.80 \%$. For group B, columns C4-B and C5-B, the ultimate loads extended between $995.07 \mathrm{kN}$ and $1013.87 \mathrm{kN}$. The improvement in the ultimate capacity was $18.30 \%$ and $20.00 \%$. For group C, column C6-C had an ultimate load of $1129.90 \mathrm{kN}$ with a considerable improvement of $28.20 \%$. For group D, columns C7-D and C8-D, the ultimate loads were $876.04 \mathrm{kN}$ and $925.43 \mathrm{kN}$, with an improvement of $7.30 \%$ and $12.30 \%$, respectively.

According to the findings in Table 8, the use of fiber glass mesh is more efficient than other types of metallic and nonmetallic mesh reinforcements in increasing the ultimate capacity. A good agreement was noted between the experimental and nonlinear approaches for all columns. 


\subsubsection{Ultimate Deflection}

Table 8 shows the ultimate deflection for all modeled columns. The deflection for the control column $\mathrm{C} 1$ was $8.12 \mathrm{~mm}$. For group $\mathrm{A}$, the maximum deflection ranged from $10.30 \mathrm{~mm}$ to $10.50 \mathrm{~mm}$ for columns C1-A to C3-A, respectively, which were higher than that of the control C1. For group B, the maximum deflection at ultimate load was $10.49 \mathrm{~mm}$ and $9.63 \mathrm{~mm}$ for columns $\mathrm{C} 4-\mathrm{B}$ and $\mathrm{C} 5-\mathrm{B}$, respectively, which was also higher than that of the control C1. For group C, column $\mathrm{C} 6-\mathrm{C}$, there was an ultimate deflection of $7.30 \mathrm{~mm}$. For group D, columns C7-D and C8-D, the ultimate deflections were 7.76 and $6.82 \mathrm{~mm}$, respectively. It can clearly be seen that good agreement was noted between the experimental and nonlinear approaches for all columns.

\subsubsection{Load-Deflection Relationship}

The relationship between the load and deflection for the modeled columns are presented in Figures 21-29. From these figures, it can clearly be seen that good agreement was noted between the experimental and nonlinear approaches for all columns.

It is possible to conclude that the FE simulations produced accurate findings when compared to the experimental results. Furthermore, the analytical deflection findings outperformed the experimental results by a mean of $15 \%$, as indicated.

\subsubsection{Energy Absorption}

Table 8 shows the ductility ratios and energy absorption values for all modeled columns. The energy absorption for the control column C1 was $4104.83 \mathrm{kN} \cdot \mathrm{mm}$. For all other columns, the energy absorption was greater than the control C1. Group D with the fiber glass mesh exhibited the smallest enhancement whereas group $C$ with the Tensarmesh exhibited a considerable enhancement. It may be concluded that by improving the ductility ratio and the energy absorption, these new composite materials improved the failure behavior.

\subsubsection{Crack Pattern}

The cracking started at an initial loading step in the molded column face near the column supports. This was due to the invisible micro-cracks in the experimental study. The cracking load was fairly lower than the experimental one. This might be acceptable as the FE analysis characterized the stage of micro-cracks. Furthermore, the wire mesh composite materials may have hidden the micro-cracks initiated in the experimental test. Conversely, the patterns of cracks at every load step showed that the crack propagation for all columns was somewhat changed compared to the experimental one due to the accuracy of the FE Ansys program in obtaining the micro-cracks. All crack patterns of the molded columns are shown in Figure 18. 


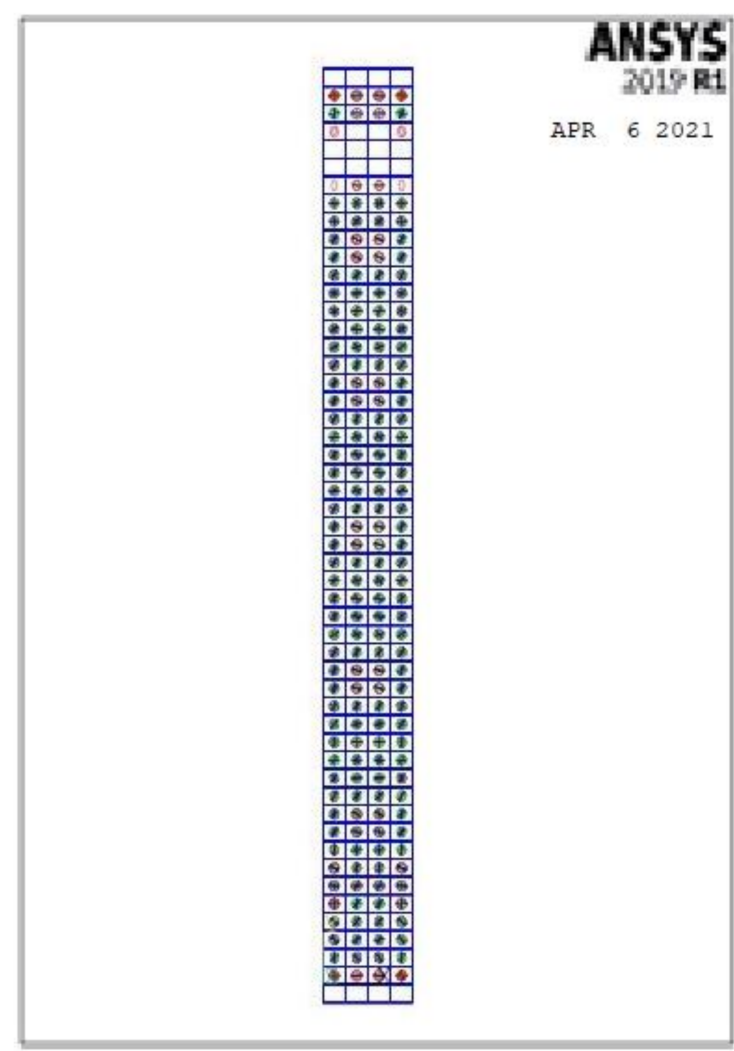

C1

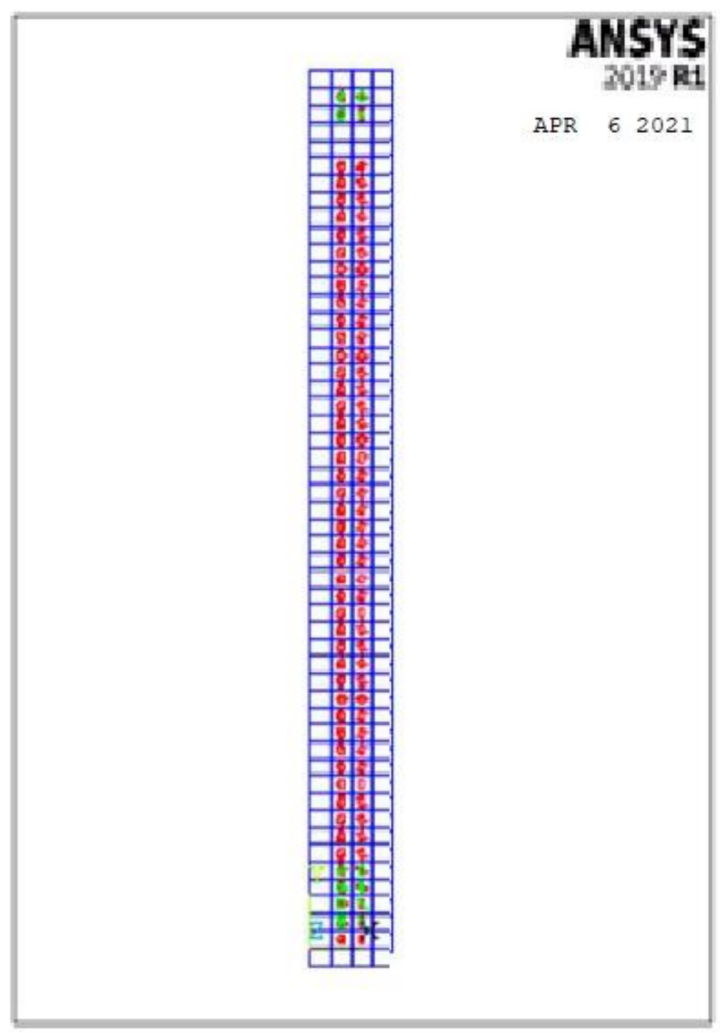

C2-A

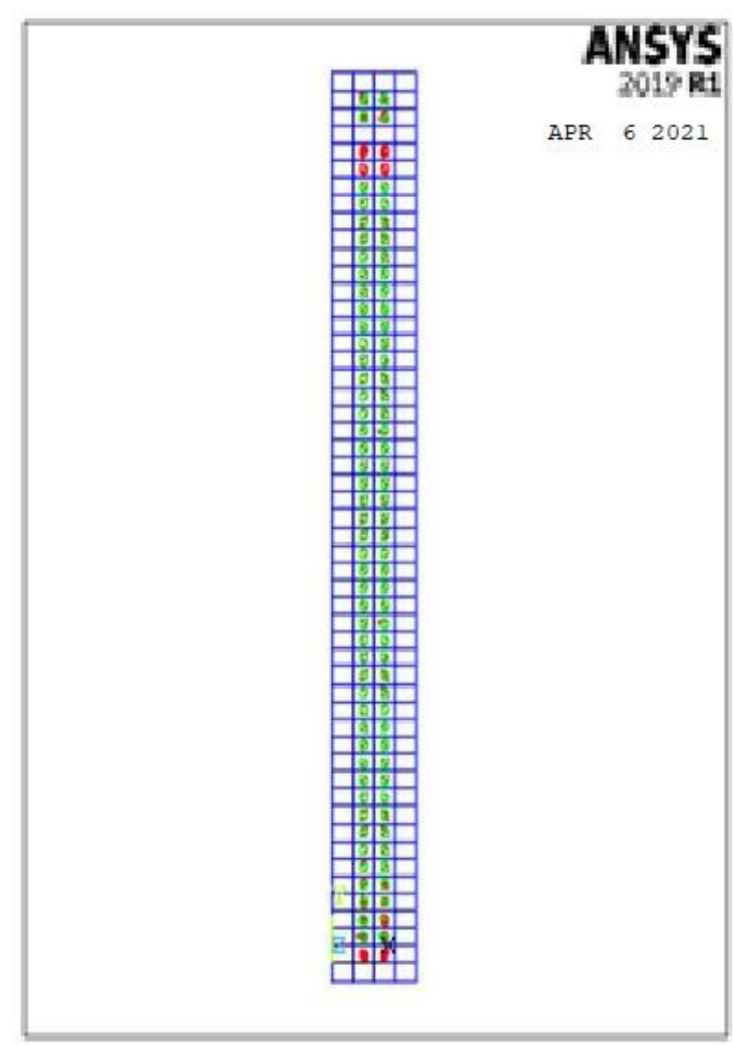

C1-A

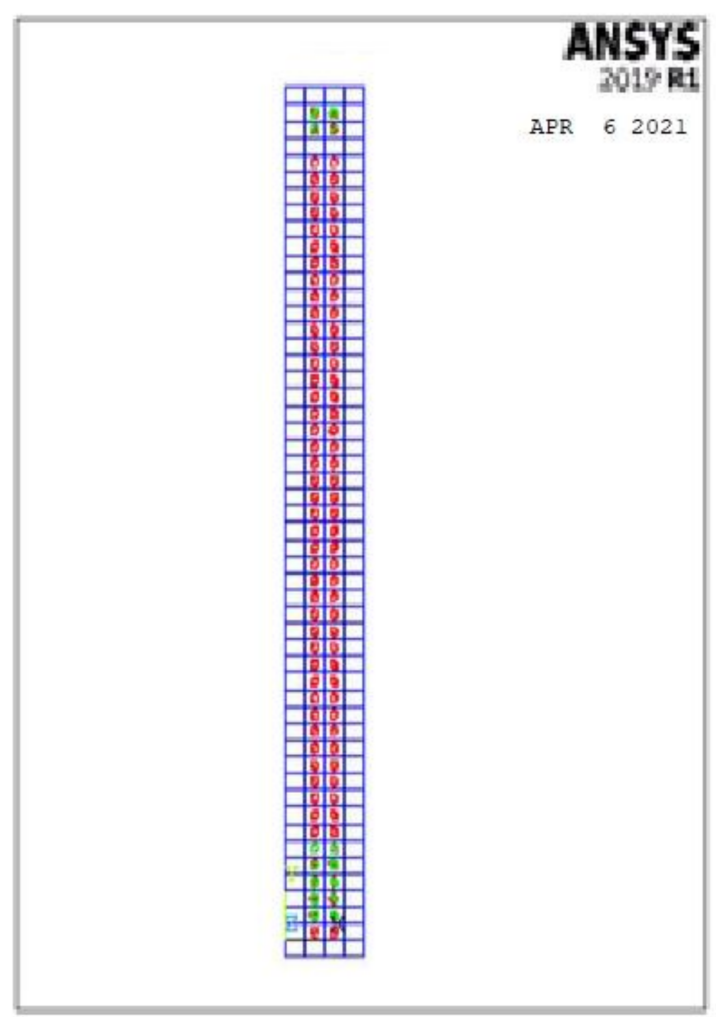

C3-A

Figure 18. Cont. 


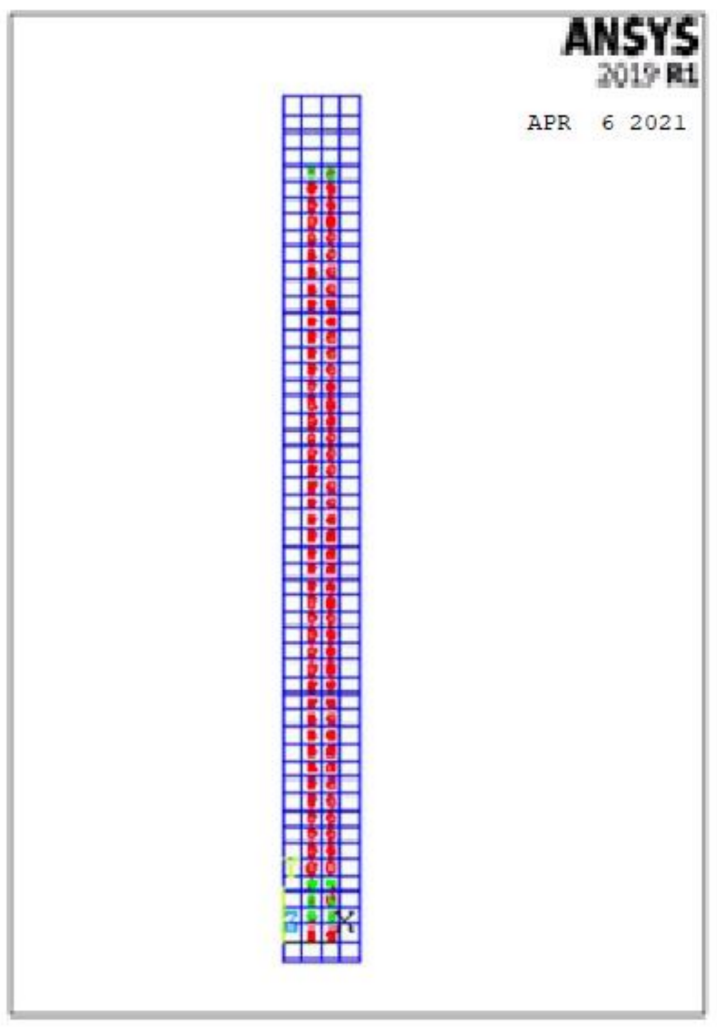

C4-B

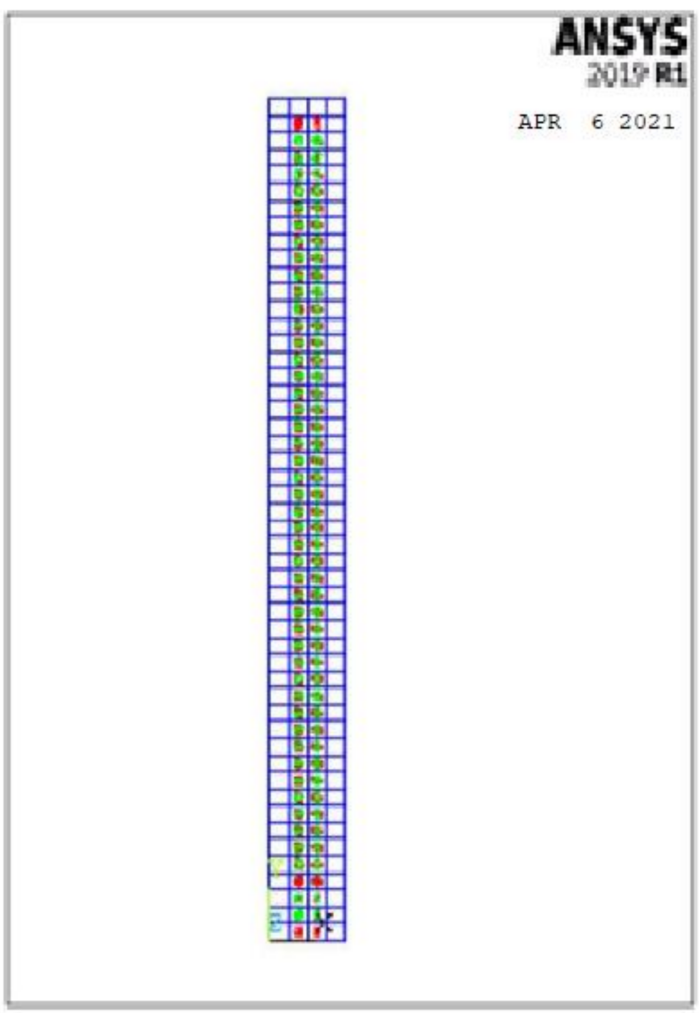

C6-C

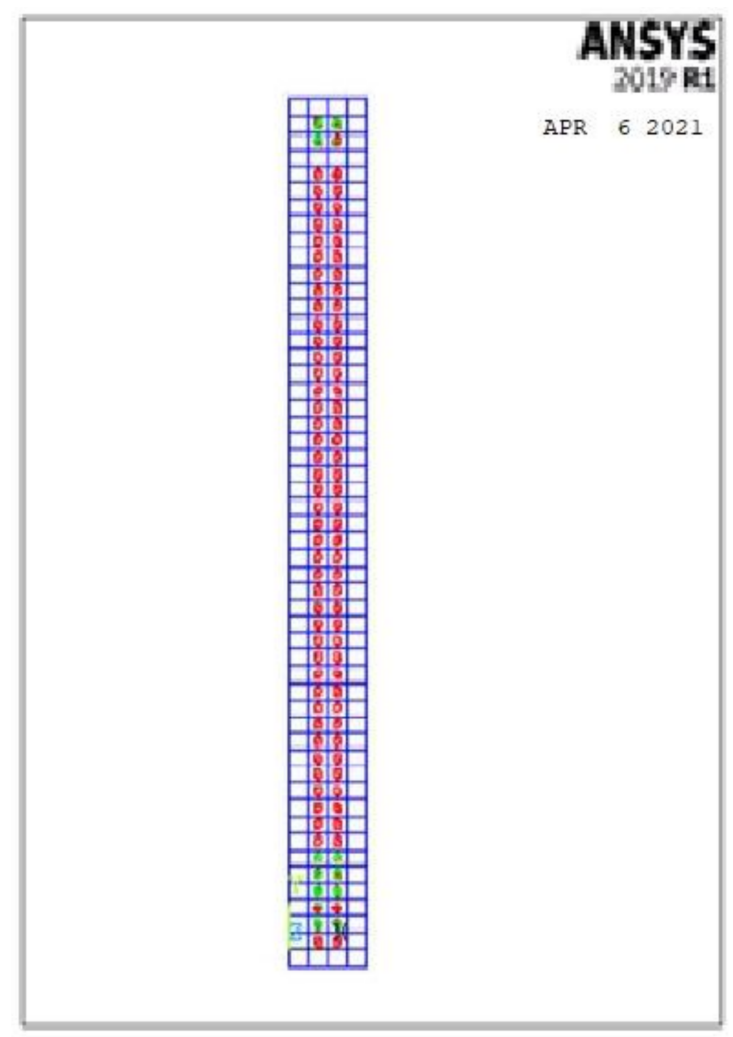

C5-B

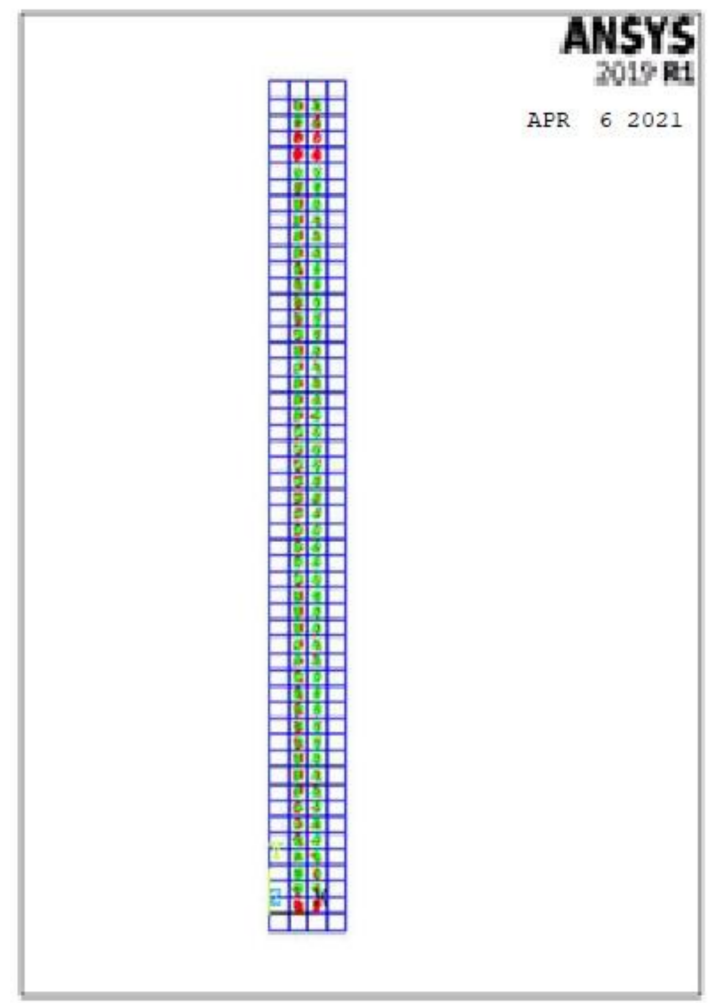

C7-D

Figure 18. Cont. 


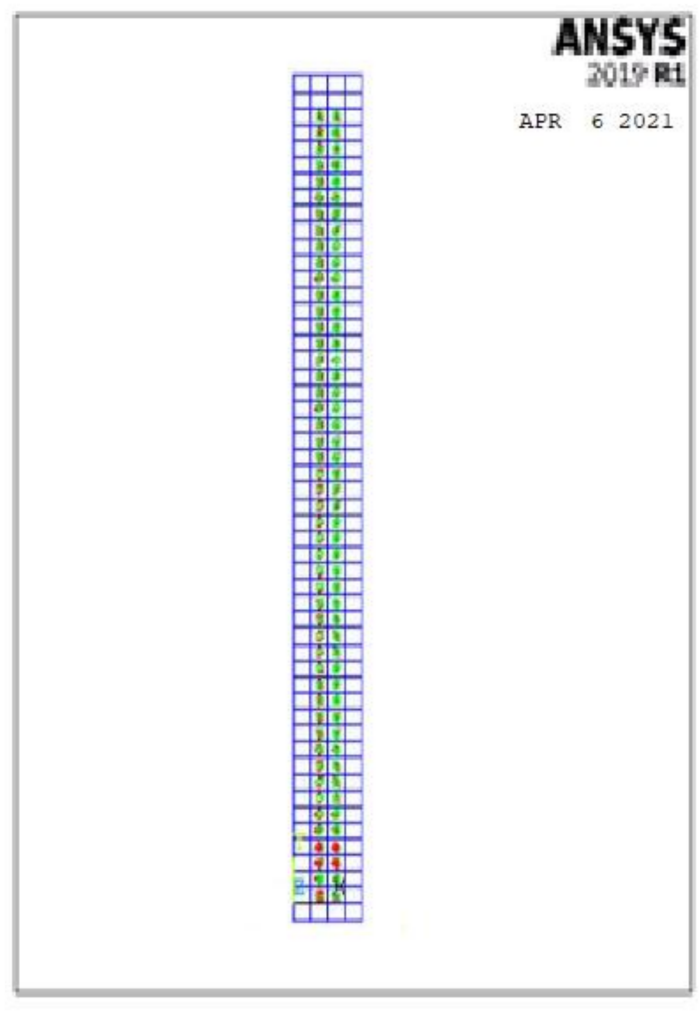

C8-D

Figure 18. Crack patterns for the modeled columns.

\section{Comparisons between Analytical and Experimental Results}

Comparison between analytical and experimental results confirmed an acceptable agreement in representing the geopolymer ferrocement HSC columns' performance in terms of first crack and ultimate deflection, first crack load and ultimate load, and crack pattern.

\subsection{Ultimate Failure Load}

Figure 19 and Table 9 show the comparison between the ultimate experimental and analytical load. There was fair agreement between the experimental and analytical ultimate loads. It is possible to conclude that the FE simulations produce accurate findings when compared to the experimental results. Furthermore, the analytical ultimate load results outperformed the experimental results by a mean of $11 \%$.

\subsection{Ultimate Deflection}

Figure 20 and Table 9 show the comparison between the ultimate experimental analytical deflections. The load-defection curves as shown in Figures 21-29 for the experimental and modeled columns showed good agreement with respect to the control column deflection. Furthermore, the analytical ultimate defection results outperformed the experimental results by a mean of $15 \%$. 


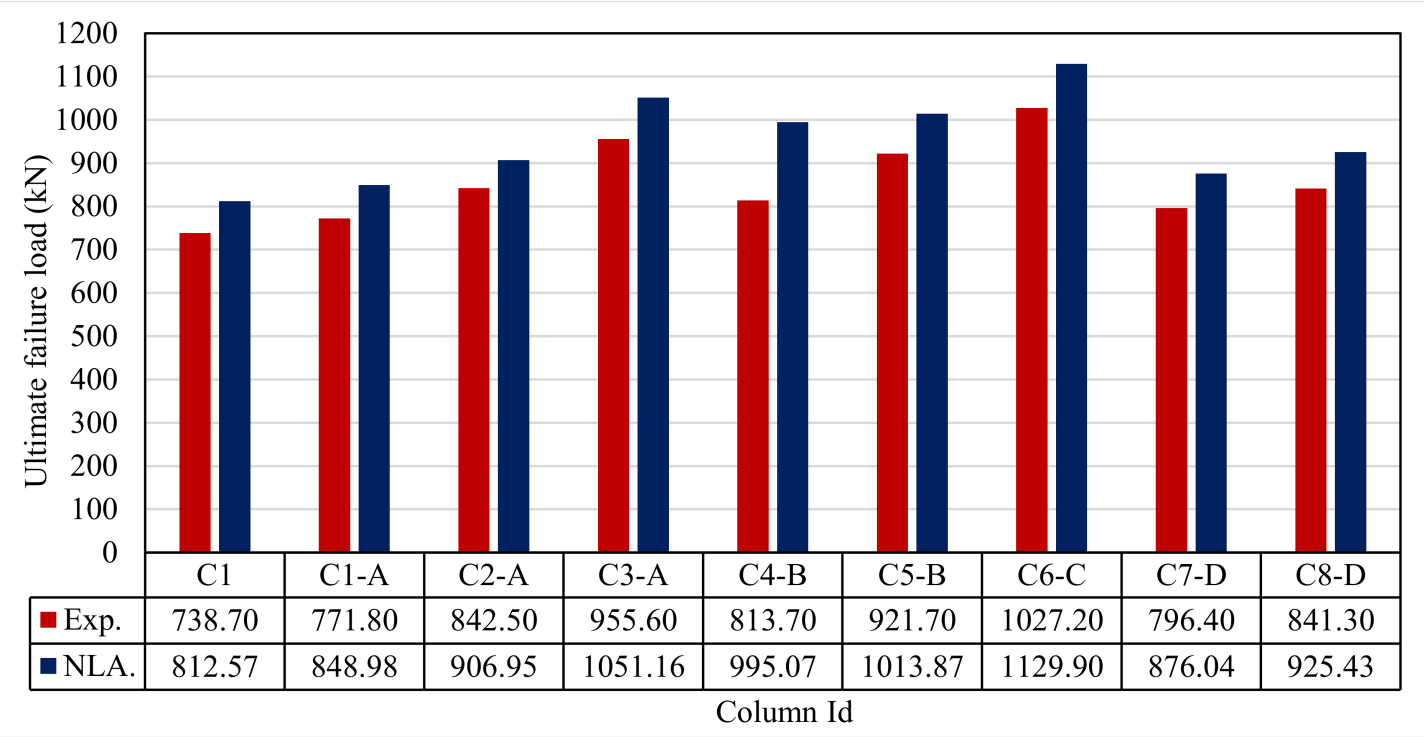

Figure 19. Comparison between Exp. and NLA ultimate loads.

Table 9. Experimental and analytical results.

\begin{tabular}{ccccccc}
\hline $\begin{array}{c}\text { Column } \\
\text { ID }\end{array}$ & $\begin{array}{c}\text { First Crack Load } \\
(\mathbf{k N})\end{array}$ & $\begin{array}{c}\text { First Crack Load } \\
(\mathbf{k N})\end{array}$ & $\begin{array}{c}\text { Ultimate Load } \\
\mathbf{( k N )}\end{array}$ & $\begin{array}{c}\text { Ultimate Load } \\
(\mathbf{k N})\end{array}$ & $\begin{array}{c}\text { Def. at Ult. Load } \\
(\mathbf{m m})\end{array}$ & $\begin{array}{c}\text { Def. at Ult. Load } \\
(\mathbf{m m})\end{array}$ \\
\hline & NLA. & EXP. & NLA. & EXP. & NLA. & EXP. \\
\hline C1 & 260.30 & 296.00 & 812.57 & 738.70 & 8.12 & 12.02 \\
\hline C1-A & 260.30 & 325.00 & 848.98 & 771.80 & 10.30 & 12.72 \\
\hline C2-A & 260.30 & 380.00 & 906.95 & 842.50 & 10.50 & 14.36 \\
\hline C3-A & 260.30 & 455.00 & 1051.16 & 955.60 & 10.31 & 14.50 \\
\hline C4-B & 260.30 & 443.00 & 995.07 & 813.70 & 10.49 & 15.45 \\
\hline C5-B & 260.30 & 449.00 & 1013.87 & 921.70 & 9.63 & 16.96 \\
\hline C6-C & 260.30 & 515.00 & 1129.90 & 1027.20 & 7.30 & 13.55 \\
\hline C7-D & 260.30 & 391.00 & 876.04 & 796.40 & 8.76 & 12.08 \\
\hline C8-D & 260.30 & 378.00 & 925.43 & 841.30 & 6.82 & 14.07 \\
\hline
\end{tabular}

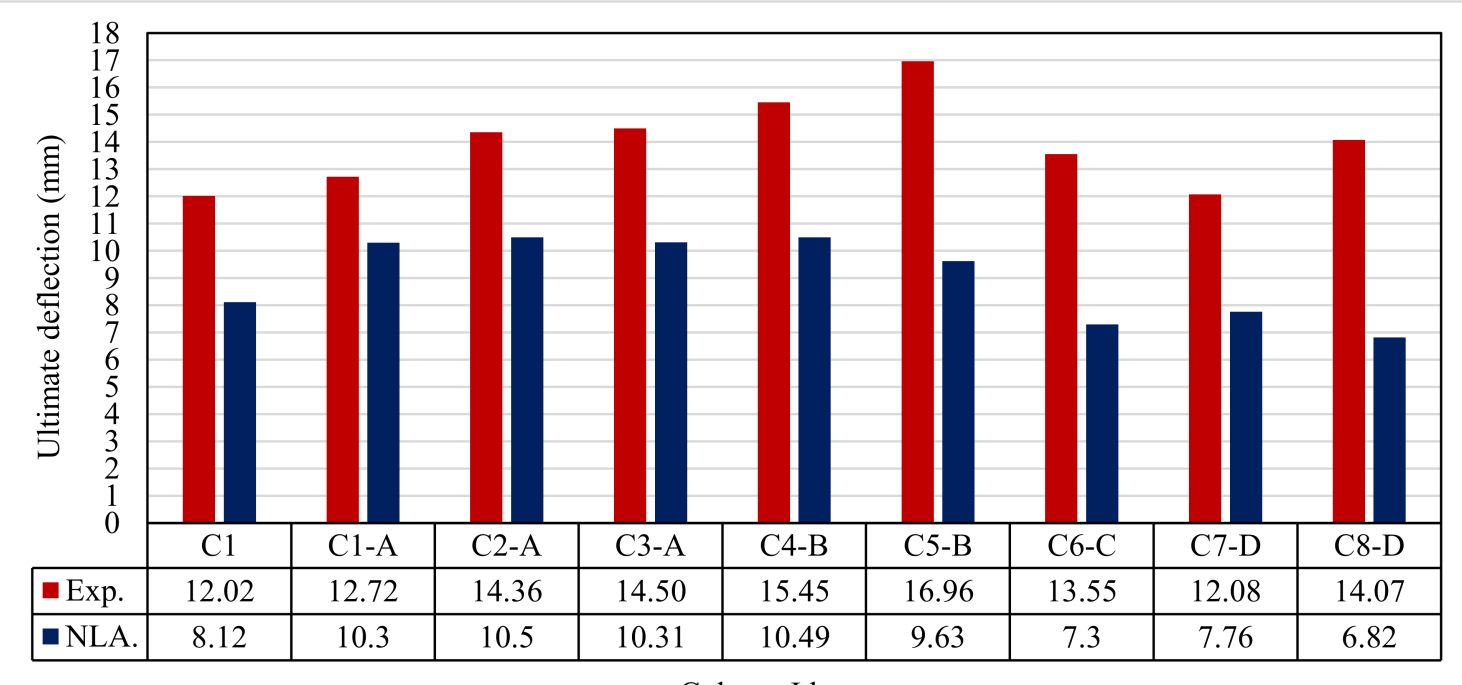

Column Id

Figure 20. Comparison between Exp. and NLA ultimate deflections. 


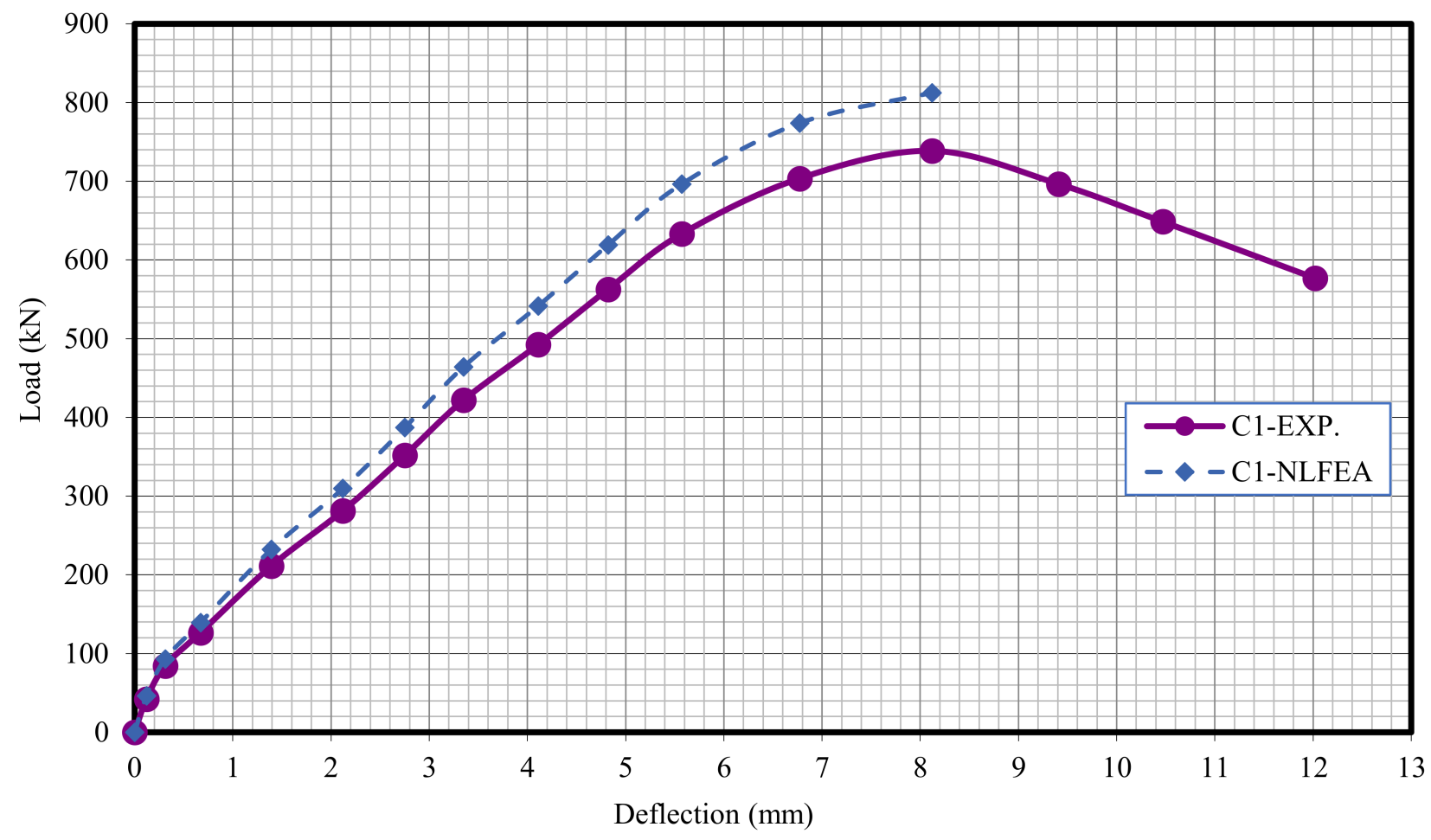

Figure 21. Load deflection of Column C1.

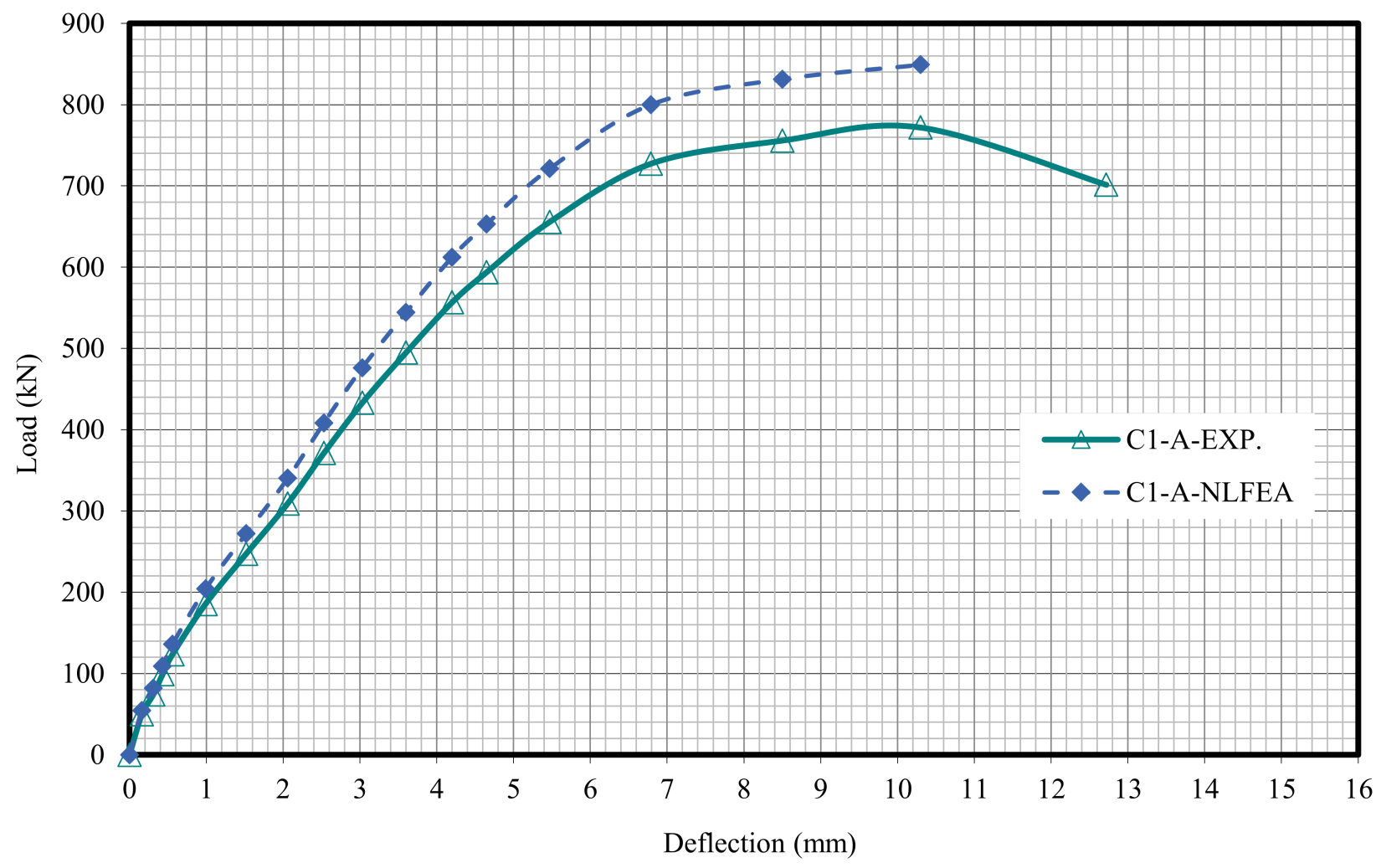

Figure 22. Load deflection of Column C1-A. 


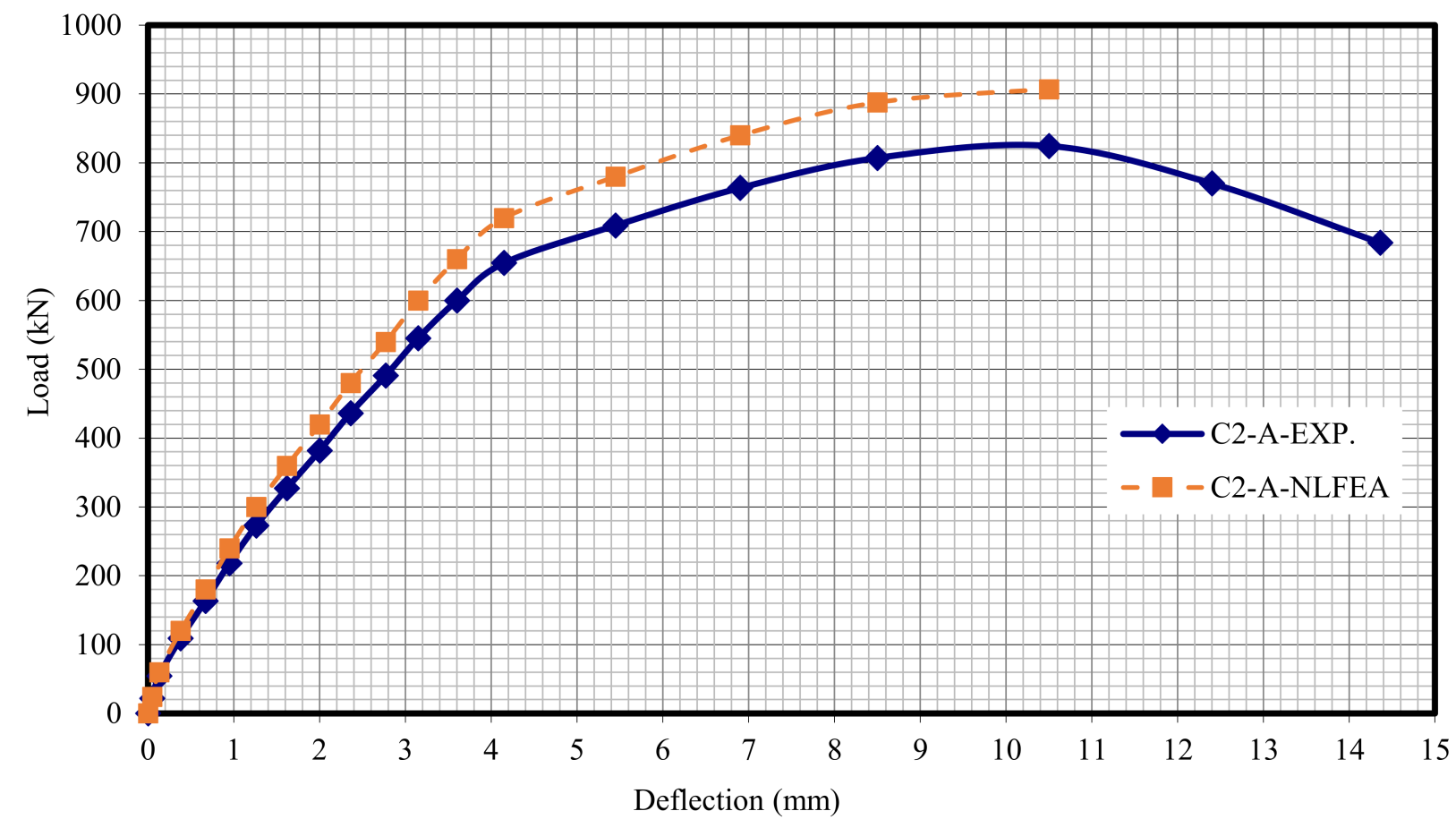

Figure 23. Load deflection of Column C2-A.

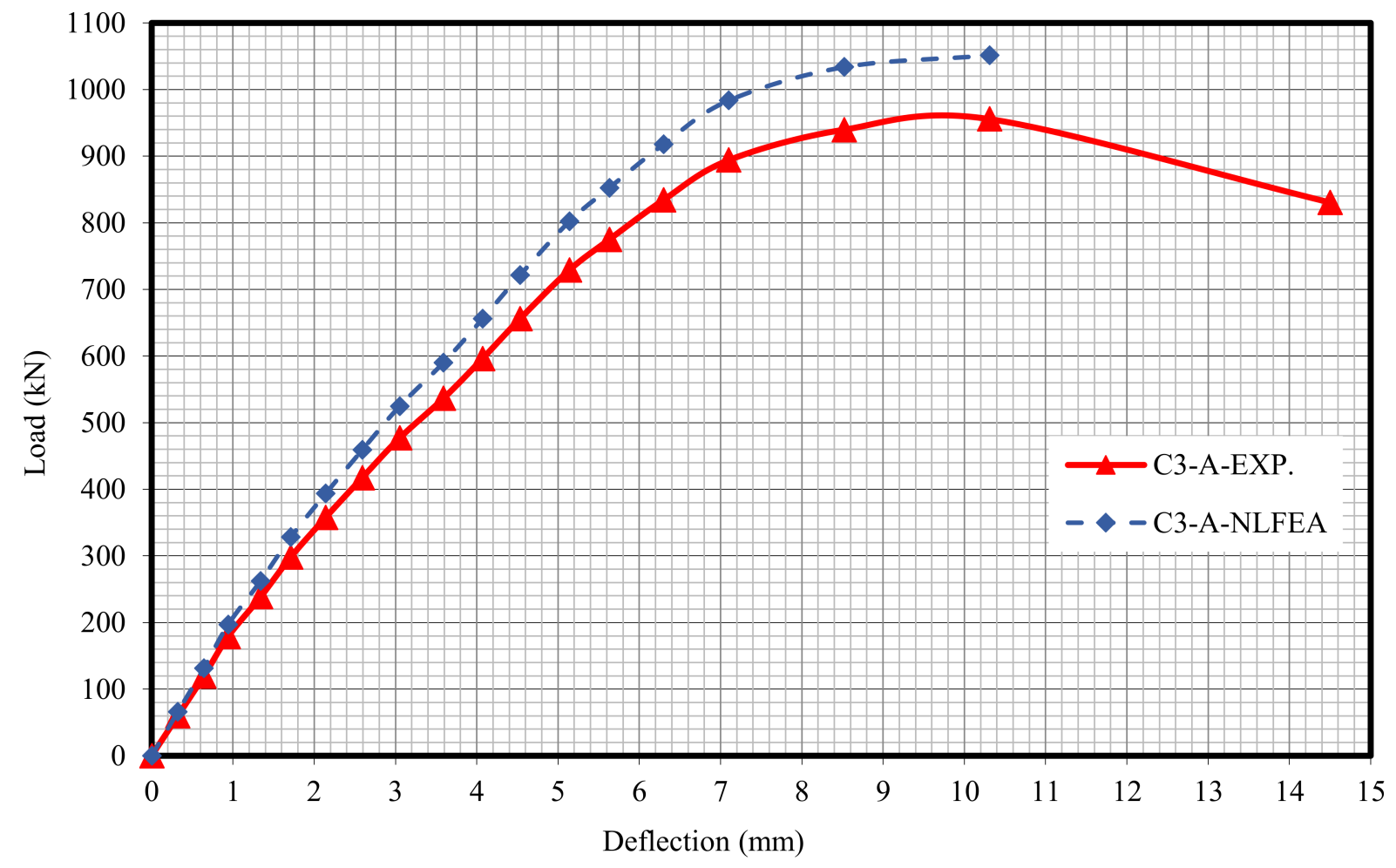

Figure 24. Load deflection of Column C3-A. 


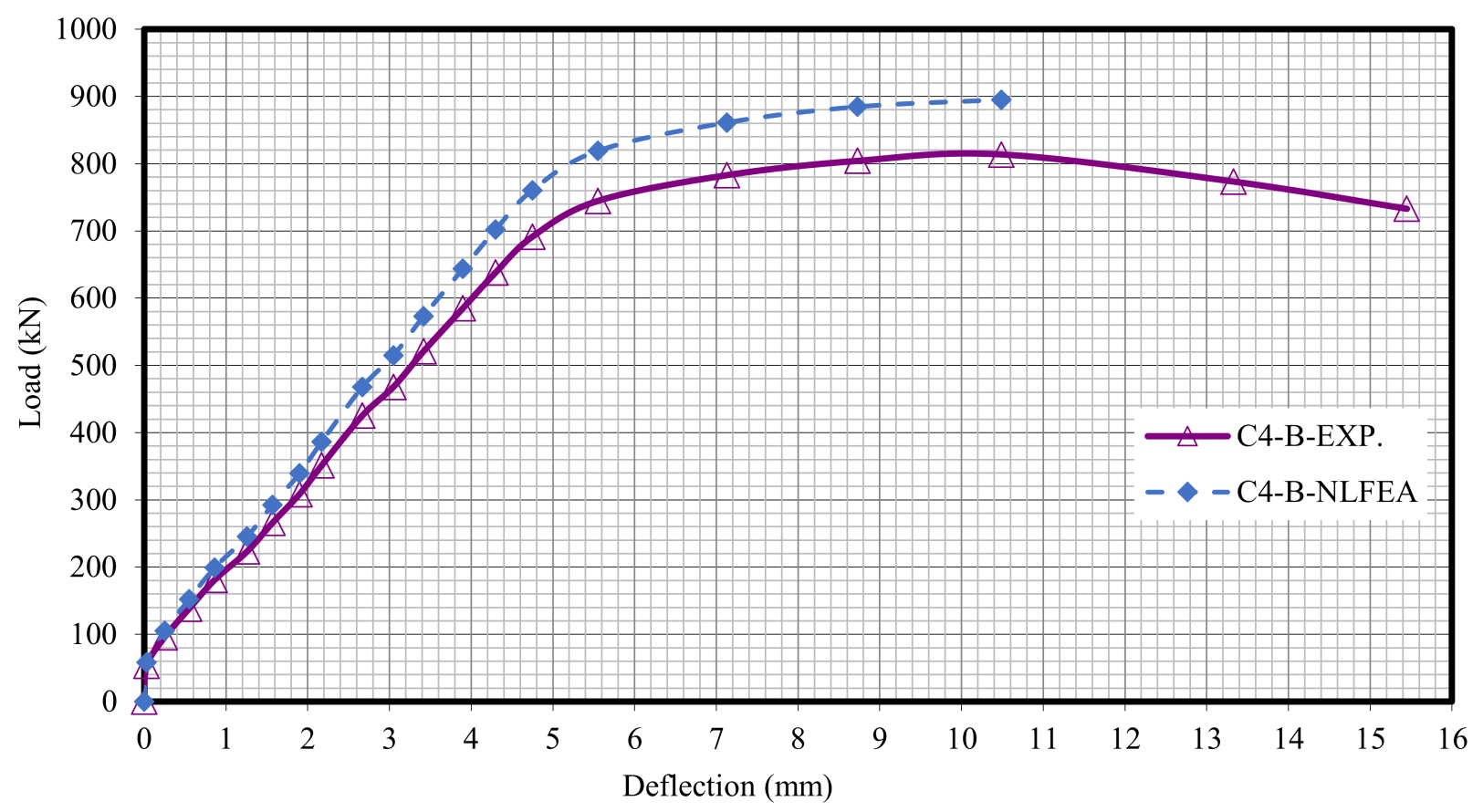

Figure 25. Load deflection of Column C4-B.

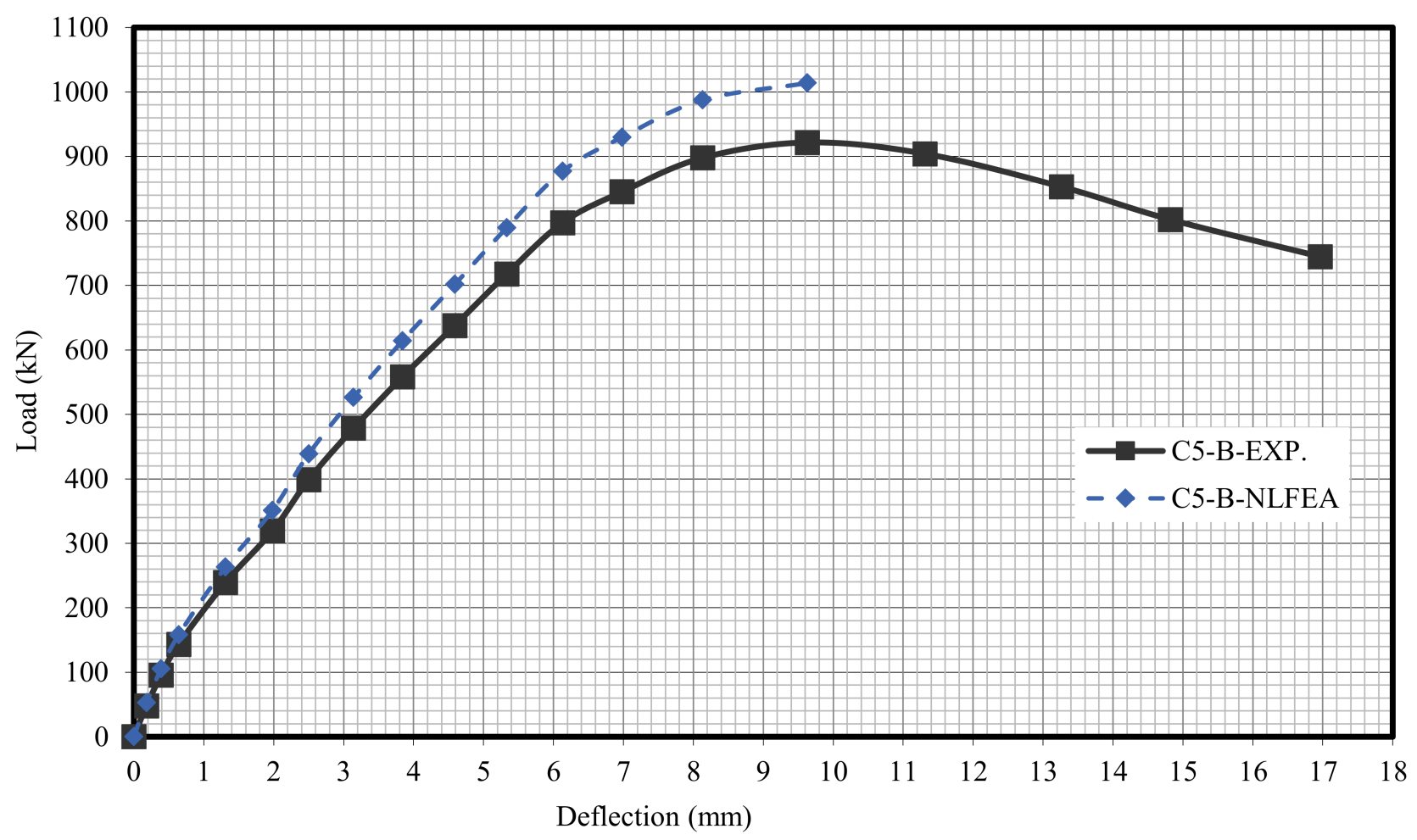

Figure 26. Load deflection of Column C5-B. 


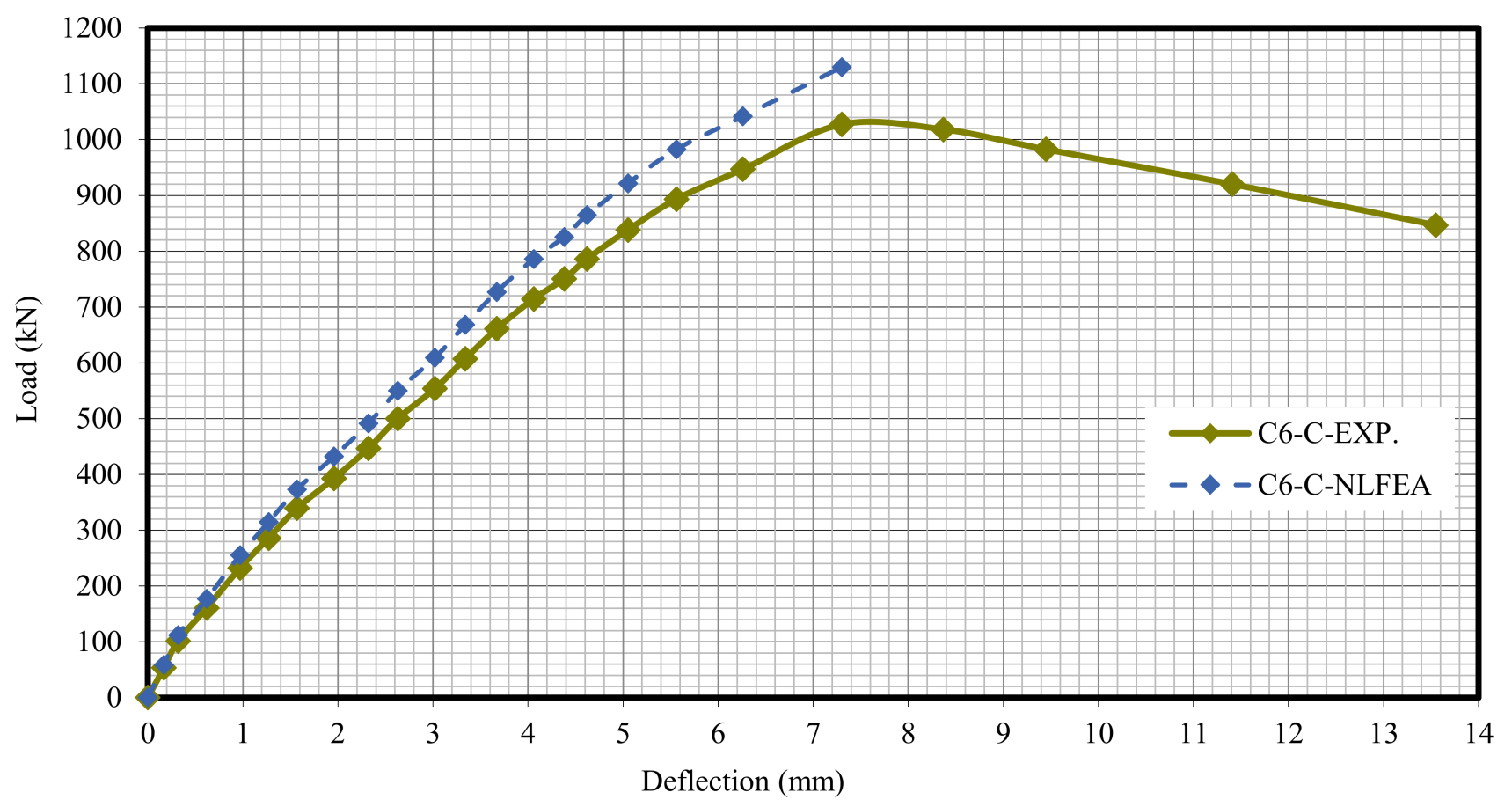

Figure 27. Load deflection of Column C6-C.

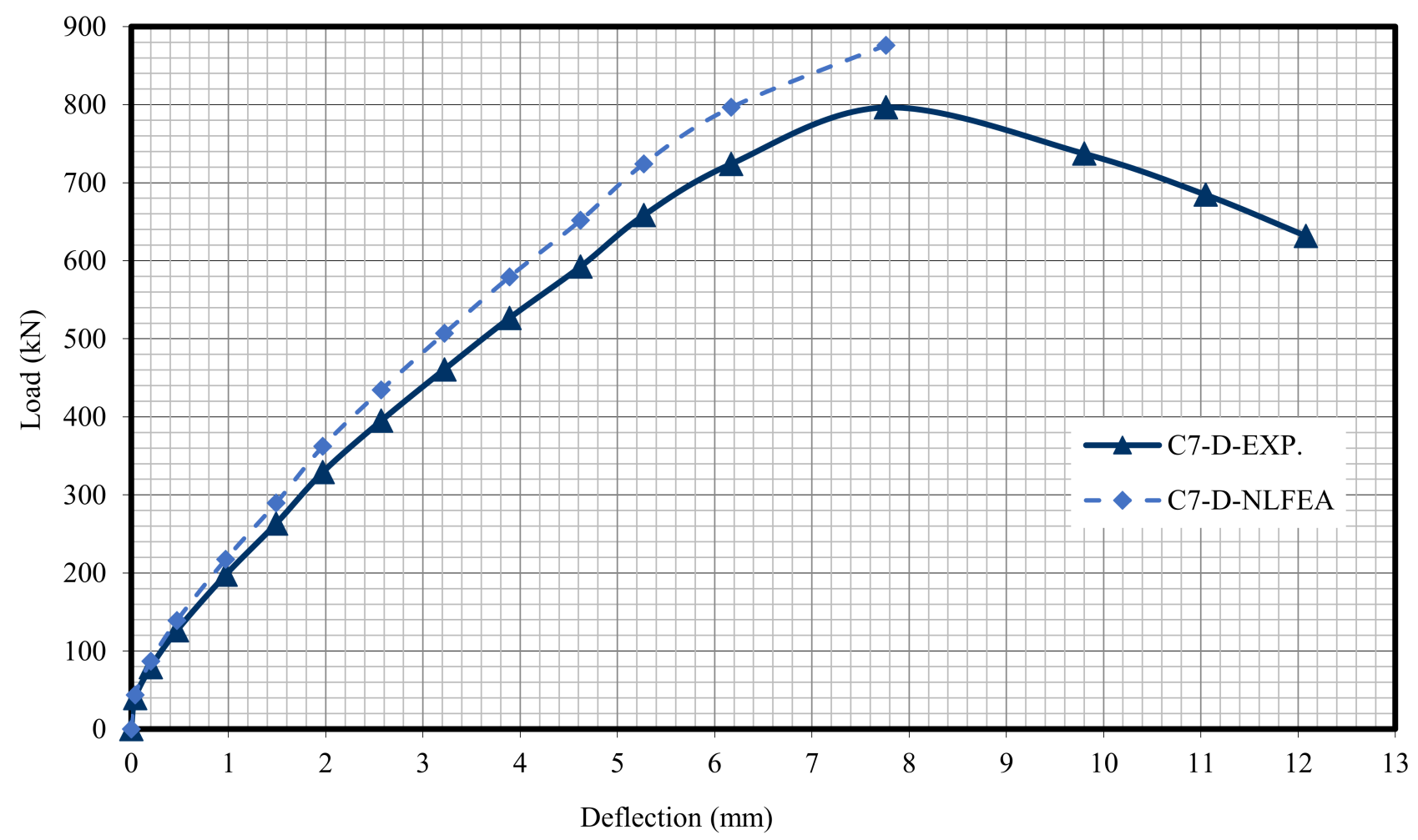

Figure 28. Load deflection of Column C7-D. 


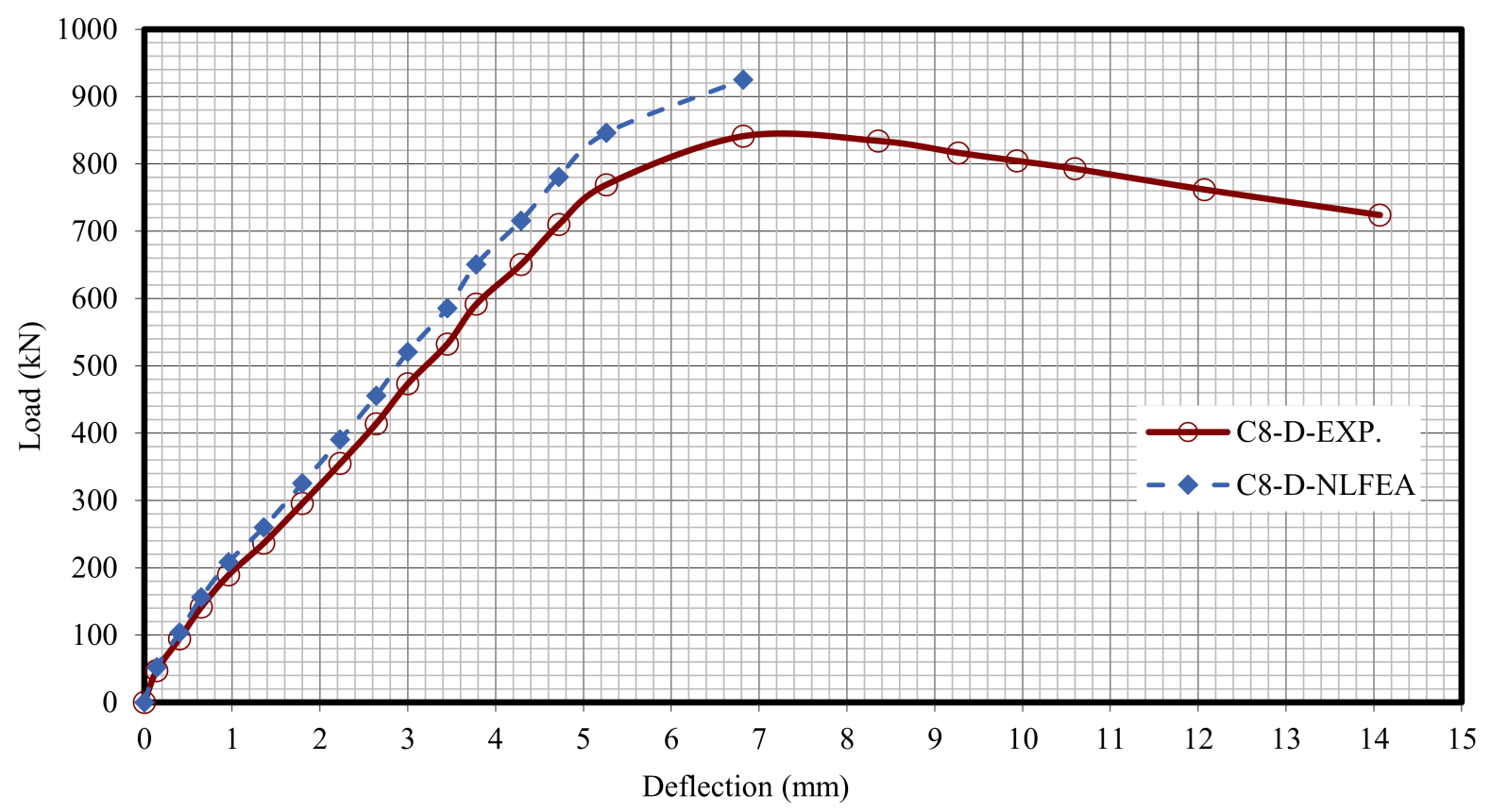

Figure 29. Load deflection of Column C8-D.

\subsection{Cracking Patterns}

Figures 30 and 31 show the comparison between the crack pattern for the experimental and modeled column samples. The micro-cracking stage, which occurs before observable cracking, is represented by the NLA forecasts. The cracking patterns at each load increment, on the other hand, demonstrated that the crack propagation for all columns differed somewhat from the experimental fracture pattern. This is due to the nonlinear finite element program's precision in determining micro- and large cracks as well as the impact of the reinforcing technique on cracking patterns, as shown in Table 9.
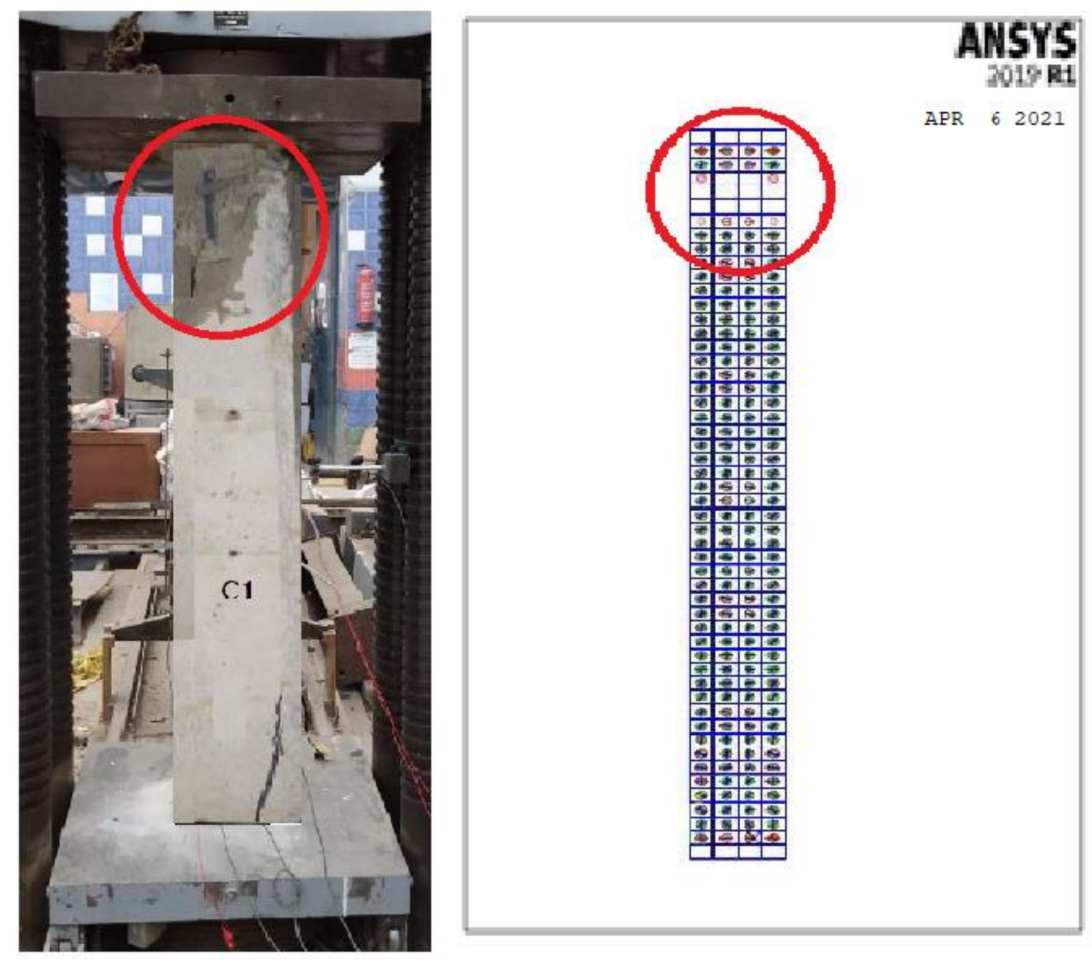

Figure 30. Crack spread for the control specimen. 

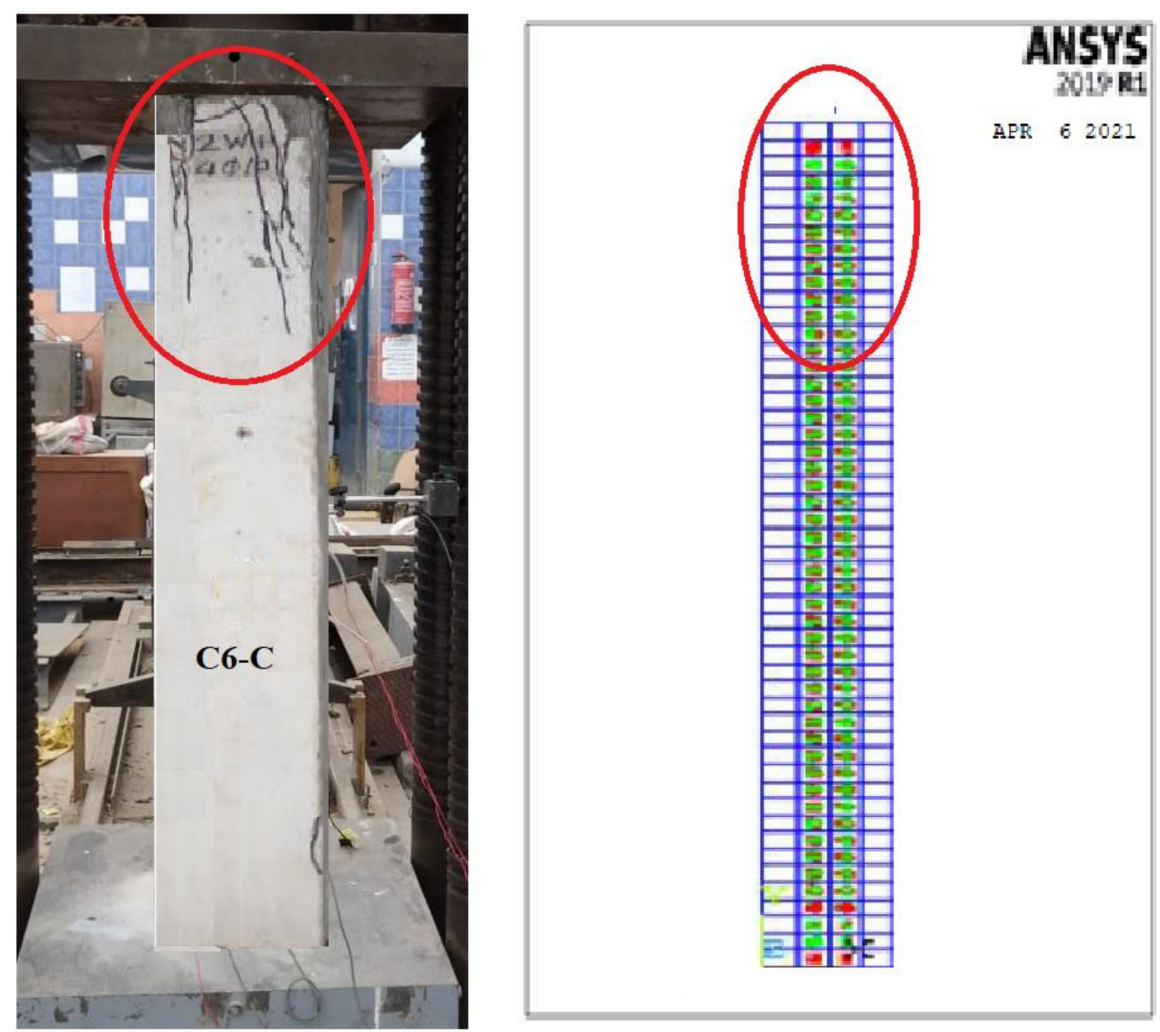

Figure 31. Cracks spread for the C6-C specimen.

\section{Conclusions}

Based on the experimental and analytical results, the following conclusions can be drawn:

1. Because of the lighter and easier handling of wire meshes compared with steel reinforcement, all wire meshes offer several improvements, especially for structures with complex shapes.

2. Increasing the volume fraction of the wire mesh reinforcement increased the initial cracks, ultimate loads, energy absorption, and ductility index.

3. Ferrocement geopolymer columns achieved higher ultimate load, ductility, and energy absorption compared to the steel reinforced concrete control column.

4. Cracks with greater number and narrower widths were observed for those ferrocement geopolymer columns compared with the steel geopolymer columns.

5. Expanded or welded ferrocement geopolymer columns showed greater ultimate failure loads than the control column. Additionally, using expanded or welded columns had a considerable effect on the ultimate failure loads, where welded wire mesh exhibited almost $28.10 \%$ compared with expanded wire mesh.

6. Column reinforced with one-layer of nonmetallic Tensar-mesh obtained the highest ultimate failure load out of all the tested columns without concrete cover spalling. Consequently, increasing the volume fraction had the main result of postponing the incidence of crack development with higher corrosion protection and high loading carrying capacity than columns reinforced with metallic reinforcement.

7. Column reinforced with one layer of fiber glass mesh obtained the smallest ultimate failure load compared with the control column.

8. The analytical procedures for first crack and ultimate load computations obtained good prediction for these loads and the column failure modes. Consequently, there were improved strength, deformation characteristics, and cracking behavior with great savings of reinforcement. 
9. The comparison of the crack patterns obtained by the FE and experimental models led to identical crack propagation for the two approaches up to failure. The inclination of the failure surfaces and the concentration of cracks of all columns were the same in both patterns.

10. The established ferrocement geopolymer columns could be successfully used as an alternative to the traditional RC columns, which could be of true merit in both developed and developing countries aside from its anticipated economic and environmental merits.

Funding: The Scientific Research at Benha University for was funded this work thorough the Research Support Program, "Research Projects Call 2017-2019-Fifth round" project no: M/5/2/14 \& “National Project Call 2018-2020-First round".

Conflicts of Interest: The author declares no conflict of interest.

\section{References}

1. Dattatreya, J.K.; Rajamane, N.P.; Sabitha, D.; Ambily, P.S.; Nataraja, M.C. Flexural behaviour of reinforced Geopolymer concrete beams. Int. J. Civ. Struct. Eng. 2011, 2, 138-159.

2. El-Sayed, T.A.; Erfan, A.M.; Abd El-Naby, R.M. Influence of Rice, Wheat Straw Ash \& Rice Husk Ash on The properties of Concrete Mixes. Jokull 2017, 67, 103-119.

3. El-Sayed, T.A.; Erfan, A.M.; El-Naby, R.M.A. Recycled rice \& wheat straw ash as cement replacement materials. J. Eng. Res. Rep. 2019, 5, 1-9.

4. El-Sayed, T.A.; MErfan, A.; MErfan, A.; El-Naby, R. Flexural Behavior of RC Beams by Using Agricultural Waste as a Cement Reinforcement Materials. J. Eng. Res. Rep. 2019, 7, 1-12. [CrossRef]

5. El-Sayed, T.A.; Shaheen, Y.B. Flexural performance of recycled wheat straw ash-based geopolymer RC beams and containing recycled steel fiber. Structures 2020, 28, 1713-1728. [CrossRef]

6. Davidovits, J. Geopolymers: Inorganic polymeric new materials. J. Therm. Anal. Calorim. 1991, 37, 1633-1656. [CrossRef]

7. Duxson, P.; Jimenez, A.M.F.; Provis, J.; Lukey, G.C.; Palomo, Á.; Van Deventer, J.S.J. Geopolymer technology: The current state of the art. J. Mater. Sci. 2006, 42, 2917-2933. [CrossRef]

8. Sofi, A.; Phanikumar, B. An experimental investigation on flexural behaviour of fibre-reinforced pond ash-modified concrete. Ain Shams Eng. J. 2015, 6, 1133-1142. [CrossRef]

9. Chun, L.B.; Sung, K.J.; Sang, K.T.; Chae, S.T. A study on the fundamental properties of concrete incorporating pond-ash in Korea. In Proceedings of the 3rd ACF International Conference- ACF/VCA, HoChiMinh, Vietnam, 11-13 November 2008.

10. Hardjito, D.; Rangan, B.V. Development and Properties of Low-Calcium Fly Ash-Based Geopolymer Concrete; Research Report GC1; Faculty of Engineering, Curtin University of Technology: Perth, Australia, 2005.

11. Bakharev, T. Geopolymeric materials prepared using Class F fly ash and elevated temperature curing. Cem. Concr. Res. 2005, 35, 1224-1232. [CrossRef]

12. Palomo, A.; Grutzeck, M.; Blanco-Varela, M.T. Alkali-activated fly ashes: A cement for the future. Cem. Concr. Res. 1999, 29, 1323-1329. [CrossRef]

13. van Jaarsveld, J.; van Deventer, J.; Lukey, G. The effect of composition and temperature on the properties of fly ash- and kaolinite-based geopolymers. Chem. Eng. J. 2002, 89, 63-73. [CrossRef]

14. Sofi, M.; van Deventer, J.; Mendis, P.; Lukey, G. Engineering properties of inorganic polymer concretes (IPCs). Cem. Concr. Res. 2007, 37, 251-257. [CrossRef]

15. Wallah, S.; Rangan, B.V. Low-Calcium Fly Ash-Based Geopolymer Concrete: Long-Term Properties; Research Report GC 2; Faculty of Engineering, Curtin University of Technology: Perth, Australia, 2006.

16. Bakharev, T. Resistance of geopolymer materials to acid attack. Cem. Concr. Res. 2005, 35, 658-670. [CrossRef]

17. Mansur, M.N.; Paramasivam, P. Ferro-cement Short Columns under Axial and Eccentric Compression. ACI Struct. J. 1990, 84, 523.

18. Kaushik, S.K.; Prakash, A.; Singh, K.K. Inelastic Buckling of Ferro-cement Encased Columns. In Proceedings of the Fifth International Symposium on Ferrcement, Manchester, UK, 6-9 September 1994; pp. 327-341.

19. Nedwell, P.J.; Ramesht, M.H.; Rafei-Taghanaki, S. Investigation into the Repair of Short Square Columns using Ferro-cement. In Proceedings of the Fifth International Symposium on Ferrcement, Manchester, UK, 6-9 September 1994; pp. $277-285$.

20. Fahmy, E.; Shaheen, Y.B.; Korany, Y. Repairing Reinforced Concrete Columns Using Ferro-cement Laminates. J. Ferro-Cem. 1999, $29,115-124$.

21. Erfan, A.M.; Ahmed, H.H.; Mina, B.A.; El-Sayed, T.A. Structural Performance of Eccentric Ferrocement Reinforced Concrete Columns. Nanosci. Nanotechnol. Lett. 2019, 11, 1213-1225. [CrossRef]

22. Erfan, A.M.; Elnaby, R.M.A.; Elhawary, A.; El-Sayed, T.A. Improving the compressive behavior of RC walls reinforced with ferrocement composites under centric and eccentric loading. Case Stud. Constr. Mater. 2021, 14, e00541.

23. Hussin, A.A.; Erfan, A.M.; El-Sayed, T.A.; Abd El-Naby, R.M. Experimental and Analytical Analysis of Lightweight Fe rrocement Composite Slabs. Eng. Res. J. 2019, 1, 88-96. 
24. Erfan, A.M.; El-Sayed, T.A. Structural Shear Behavior of Composite Box Beams Using Advanced Innovated Materials. J. Eng. Res. Rep. 2019, 5, 1-14. [CrossRef]

25. Erfan, A.M.; El-Sayed, T.A. Shear Strength of Ferrocement Composite Box Section Concrete Beams. Int. J. Sci. Eng. Res. 2019, 10, 260-279.

26. El-Sayed, T.A.; Shaheen, Y.B.; Ahmed, H.H.; Yussef, A.K. Flexural performance of GGBS-based geopolymer ferrocement beams. Int. J. Sci. Eng. Res. 2021, 12, 1-40.

27. El-Sayed, T.A. Performance of Porous Slabs Using Recycled Ash. Polymers 2021, 13, 3319. [CrossRef]

28. E.C.P. 203/2020. Egyptian Code of Practice: Design and Construction for Reinforced Concrete Structures; Housing and Building National Research Center: Cairo, Egypt, 2020.

29. El-Sayed, T.A.; Erfan, A.M. Improving shear strength of beams using ferrocement composite. Constr. Build. Mater. 2018, 172, 608-617. [CrossRef]

30. ANSYS. Engineering Analysis System User's Manual, Vol. 1E2, and Theoretical Manual; Revision 8.0; Swanson Analysis System Inc.: Houston, PA, USA, 2005. 